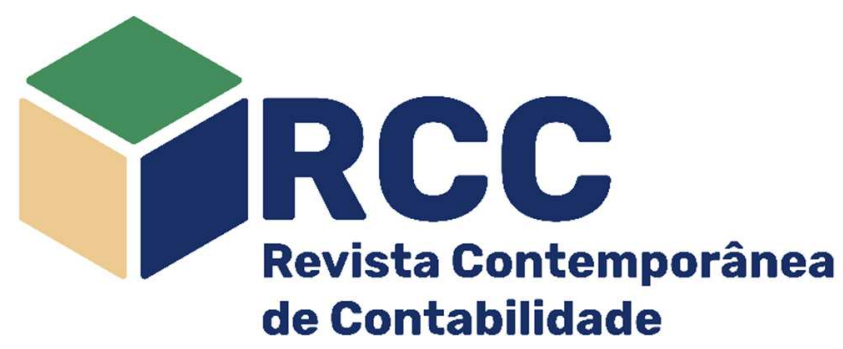

\title{
Determinantes do nível de divulgação das informações por segmento (CPC 22) das empresas brasileiras de capital aberto listadas no IBrX-50
}

\author{
Determinants of the level of disclosure of information by segment (CPC 22) of public traded Brazilian \\ companies listed in the IBrx-50
}

\begin{abstract}
Determinantes del nivel de divulgación de información por segmento (CPC 22) de las empresas brasileñas que cotizan en bolsa listadas en el IBrx-50
\end{abstract}

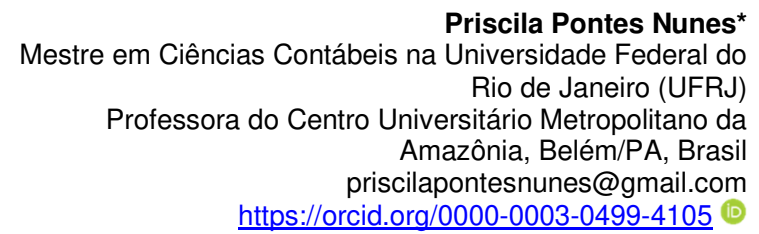

Universidade Federal do

Rio de Janeiro (UFRJ)

https://orcid.org/0000-0003-0499-4105 (D)

\author{
Odilanei Morais dos Santos \\ Doutor em Controladoria e Contabilidade na \\ Universidade de São Paulo (USP) \\ Professor do Programa de Pós-Graduação em Ciências \\ Contábeis (UFRJ), Rio de Janeiro/RJ, Brasil \\ profodilanei@gmail.com \\ https://orcid.org/0000-0002-4897-8353 (1)
}

José Augusto Veiga da Costa Marques

Pós-Doutor em Controladoria e Contabilidade na

Universidade de São Paulo (USP)

Professor do Programa de Pós-Graduação em Ciências

Contábeis (UFRJ), Rio de Janeiro/RJ, Brasil

joselaura@uol.com.br

https://orcid.org/0000-0002-8673-961X (1)

Endereço do contato principal para correspondência* Av. Visconde de Souza Franco, 72 - Reduto, CEP: 66053-000 - Belém, PA, Brasil

\section{Resumo}

Este estudo verificou quais características corporativas são relacionadas com o índice de divulgação (ID) das empresas referente as informações por segmentos requeridas pelo CPC 22. Realizou-se um estudo com dados de 2010 a 2016 de empresas listadas no índice IBrX-50. Aplicou-se um checklist contendo os requerimentos do CPC 22 e utilizou-se uma regressão MQO para identificar as determinantes sobre o índice de divulgação. Foi evidenciado um ID médio total de 57,72\%, com média máxima de $86,55 \%$ e mínima de $28,59 \%$. As variáveis endividamento, quantidade de segmentos reportados, divulgação primária das informações por região geográfica e clientes significativos foram estatisticamente significantes e com sinais esperados, enquanto as demais variáveis não foram significativas ou tiveram sinais invertidos. Os resultados contribuem para o entendimento do nível de divulgação das empresas brasileiras em relação as informações por segmentos e suscita questionamentos sobre a relevância dos itens de evidenciação requeridos pelo CPC 22.

Palavras-chave: CPC 22; Informações por Segmento; Índice de Divulgação

\section{Abstract}

This study verified which corporate characteristics are related to the companies' disclosure index (ID) for segment information required by CPC 22. The study was realized with data from 2010 to 2016 of companies listed in the $\mathrm{IBrX}-50$ index. A checklist containing the requirements of $\mathrm{CPC} 22$ was applied and a MQO regression was used to identify the determinants on the disclosure index. It was evidenced a total average ID of $57,72 \%$, with a maximum average of $86,55 \%$ and a minimum of $28,59 \%$. The variables indebtedness, number of segments reported, primary disclosure of information by geographic region and significant clients were statistically significant and with expected signs, while the other variables were not significant or had signs reversed. The results contribute to the understanding of the level of disclosure of Brazilian companies in 
relation to segment information and raises questions about the relevance of the disclosure items required by CPC 22

Keywords: CPC 22; Information by Segment; Disclosure Index

\section{Resumen}

Este estudio verificó qué características corporativas están relacionadas con el índice de divulgación de las empresas referente a las informaciones por segmentos requeridas por el CPC 22. Se realizó un estudio con datos de 2010 a 2016 de empresas listadas en el índice IBrX-50. Se aplicó un checklist conteniendo los requerimientos del CPC 22 y se utilizó una regresión MQO para identificar los determinantes sobre el índice de divulgación. Se evidenció un ID promedio total del 57,72\%, con una media máxima de 86,55\% y mínima del $28,59 \%$. Las variables de endeudamiento, cantidad de segmentos reportados, divulgación primaria de las informaciones por región geográfica y clientes significativos fueron estadísticamente significantes y con señales esperadas, mientras que las demás variables no fueron significativas o tuvieron signos invertidos. Los resultados contribuyen al entendimiento del nivel de divulgación de las empresas brasileñas en relación a las informaciones por segmentos y suscita cuestionamiento sobre la relevancia de los ítems de evidencia requeridos por el CPC 22.

Palabras clave: CPC 22; Información por Segmento; Índice de Divulgación

\section{Introdução}

Para os investidores, há diversos meios de se obter as informações necessárias sobre a situação econômica e financeira das empresas, sendo que uma das principais fontes é por meio da contabilidade (SCHVIRCK, 2014). De acordo com ludícibus, Martins e Carvalho (2005), a contabilidade surgiu da necessidade de monitorar o crescimento do capital e evolução patrimonial das empresas. Com o passar dos anos e com o desenvolvimento econômico das entidades, a contabilidade se aperfeiçoou e virou um complexo sistema de informação e avaliação, que busca diminuir a escassez informacional de seus usuários referente as empresas de seus interesses (IUDÍCIBUS; MARTINS; CARVALHO, 2005).

A teoria da agência aborda a relação entre os acionistas e gestores, que é definida como relação de agência, que surge a partir de um contrato em que uma ou mais pessoas, denominado de 'principal', delegam alguns serviços para uma outra pessoa, chamada de 'agente', cujo 'agente' fica responsável para tomar decisões em nome do 'principal' (JENSEN; MECKLING, 1976). Nessa relação, o 'principal' é o acionista e o 'agente' é o gestor.

Eisenhardt (1989) explica que nem sempre o gestor tomará decisões para suprir os interesses dos investidores, pois há possibilidades de o administrador gerir para alcançar metas pessoais, podendo prejudicar os resultados reais da empresa. Isto é possibilitado pelo maior acesso as informações das empresas que os gestores possuem em comparação aos usuários externos, então estas situações podem gerar conflitos de interesses entre os gestores e acionistas, o que é conhecido como conflito de agência.

A teoria explana que esse maior acesso as informações por parte dos gestores, gera a assimetria informacional. Dessa forma, para reduzir esta assimetria, a contabilidade aparece como uma fundamental ferramenta (IUDÍCIBUS; MARTINS; CARVALHO, 2005). A assimetria informacional é amenizada não só com as informações contábeis exigidas de forma obrigatória pelos órgãos reguladores, mas também pelas informações econômicas e financeiras reportadas de forma voluntária.

Healy e Palepu (2001) e Lambert, Leuz e Verrecchia (2007) abordam a divulgação voluntária como uma determinante para a diminuição da assimetria informacional no mercado de capitais. Dessa forma, os usuários externos começaram a exigir cada vez mais informações, obrigatórias ou voluntárias, para amenizar a assimetria informacional por meio de uma maior transparência da situação da empresa (LÉLIS et al., 2008). Um exemplo foi o incentivo dado pelo American Institute of Certified Public Accountants (AICPA) e pela Securities and Exchange Commission (SEC) no início dos anos 1970 para que as empresas norte-americanas apresentassem, voluntariamente, seus relatórios de forma segmentada (MOURAD, 2009).

Desde então, houve uma evolução normativa referente à divulgação das informações por segmento de modo que hoje trata-se de divulgação obrigatória, seja por força do Statement of Financial Accounting Standards (SFAS) no 131 - Disclosures About Segments of an Enterprise and Related Information (SFAS 131) emitido pelo Financial Accounting Standards Board (FASB) no ambiente norte-americano, ou o International Financial Reporting Standards (IFRS) no 8 - Operating Segments (IFRS 8) emitido pelo International Accounting Standards Board (IASB) referente às normas internacionais, que no Brasil está contemplado no Pronunciamento Técnico CPC no 22 - Informações por Segmento (CPC 22), do Comitê de Pronunciamento Contábil (CPC).

O CPC 22 foi divulgado no Brasil em 31/07/2009 e possui como objetivo a exigência da divulgação das informações por segmentos da entidade. Estas informações são exigidas para permitir a avaliação, pelos usuários das demonstrações contábeis, da natureza e dos efeitos financeiros de cada atividade que as entidades estão envolvidas e os ambientes econômicos onde operacionalizam.

Há diversas informações exigidas pelo CPC 22 para divulgação. Conforme as classificações de Souza (2013) estas informações podem ser divididas em categorias gerais, tais como: a) informações gerais sobre 
os segmentos (classificação e critérios de identificação dos segmentos, por exemplo); b) informações sobre área geográfica (segregação de informações por países e por regiões brasileiras); c) informações sobre produtos e serviços de cada segmento; d) informações sobre os principais clientes (apresentação se há dependência de principais clientes); e) informações sobre o lucro ou prejuízo, ativo e passivo de cada segmento; f) mensuração (divulgação das bases de contabilização para as transações entre segmentos, por exemplo); e g) conciliação (apresentação das conciliações das informações de cada segmento, como os ativos, passivos, receitas, lucro ou prejuízo, com as informações totais da entidade).

Em que pese o caráter de obrigatoriedade quanto aos requerimentos de divulgação exigido pelas normas, estudos anteriores mostram que, no Brasil, por exemplo, o nível de divulgação das informações por segmento ainda não atingiu o nível de divulgação requerido pelo CPC 22. Veja-se os resultados de Schvirck (2014) em que apenas $43 \%$ das 510 companhias analisadas publicaram relatórios com dois ou mais segmentos, ou ainda os resultados de Aillón et al. (2013) que apuraram um baixo nível de divulgação por parte das empresas, alcançando percentual de apenas 48\%, sugerindo que o nível de disclosure é insatisfatório.

De forma geral, os estudos anteriores objetivaram identificar quais fatores influenciaram a escolha do segmento primário (TALHA; SALIM, 2010); como foram definidos os segmentos publicados (SCHVIRCK; LUNKES; GASPARETTO, 2013); qual o impacto da divulgação das informações por segmento no desempenho da empresa (SCHVIRCK, 2014) ou, então, a aderência da divulgação das informações por segmento em setores específicos (FERNANDES, 2009).

Dada a abordagem dos estudos anteriores, acredita-se que ainda é necessário compreender a aplicação da norma CPC 22 no contexto brasileiro e, assim, inferir sobre o nível de aderência das empresas brasileiras aos requerimentos normativos, para depois tentar identificar quais características das empresas se relacionam com esses índices de divulgação.

Assim, diante do contexto apresentado, tem-se como questão de pesquisa: Quais as características das empresas que compõem o Índice Brasil 50 (IBrX-50) que possuem relação com o índice de divulgação das informações por segmentos?

Portanto, este estudo tem como objetivo verificar quais variáveis são relacionadas com o índice de divulgação das empresas que atuam no mercado de capitais brasileiro que compõem o IBrX-50 no que tange aos requerimentos da norma contábil de informações por segmento (CPC 22).

No contexto em que as empresas estão cada vez mais atuando em escala global e diversificando seus negócios, se torna necessário a divulgação das informações contábeis por segmento, objetivando evitar distorções nas análises das demonstrações contábeis. Desta forma, este trabalho justifica-se pela relevância em verificar se as empresas de capital aberto brasileiras estão atendendo aos requerimentos da norma contábil sobre informações por segmento, para, assim, gerar informações relevantes e fidedignas sobre suas atividades de forma individual.

Também é relevante verificar se as divulgações por segmento estão consolidadas ou não, pois já se passaram em torno de 10 anos desde a adoção do IFRS no Brasil e 8 anos da adoção do CPC 22. Muitas pesquisas foram feitas durante os primeiros anos de vigência do CPC 22 e a maioria identificou baixos níveis de divulgação. Porém, há uma escassez de estudos recentes sobre este tema. As comparações da divulgação mais recentes das informações por segmento com as divulgações mais antigas servem para avaliar a evolução da norma no Brasil.

Além disso, as evidências podem alimentar o processo decisório do IASB, dado que o órgão colocou em revisão o IFRS 8 em março de 2017, abrindo consulta pública sobre propostas de melhoria do IFRS 8 . Tal consulta pública ficou aberta até o mês de julho daquele ano e ainda não se tem um posicionamento final do IASB, o que abre margens para que as evidências desse estudo tenham relevância no processo normativo.

Outro ponto a destacar é a inclusão de novas variáveis aos modelos econométricos normalmente utilizados na literatura, tais como a quantidade de segmentos reportados; se o reporte primário da empresa é por região geográfica ou por área de negócio; dependência de clientes significativos; e independência do conselho de administração. A inclusão de novas variáveis aos modelos se justifica pela tentativa de incremento no poder explicativo encontrado em estudos anteriores, como em Aillón et al. (2013), com $\mathrm{R}^{2}$ de 6,7\%; Schvirck (2014) com 11,63\%; Souza (2013) com 23,30\%; Souza, Schäfer e Gasparetto (2016) com 27\% e Weschenfelder e Mazzioni (2014) com R² de 35\%.

\section{Referencial Teórico}

\subsection{Teoria da Divulgação}

A teoria da divulgação é uma linha de pesquisa que estuda as particularidades da divulgação das informações econômicas e financeiras, como os motivos da divulgação, os reflexos dessa divulgação no mercado de capital etc. (SALOTTI; YAMAMOTO, 2005).

Verrecchia (2001) elaborou um ensaio teórico sobre o tema "divulgação", em que afirmou que, naquele momento, ainda não se tinha uma teoria abrangente e unificada sobre a divulgação e sim que a teoria da divulgação estava sendo representada por uma mistura de perspectivas diferentes, na qual cada uma 
tentava explicar uma pequena parte do todo.

Desse modo, em uma tentativa de orientar os pesquisadores, o autor sugeriu três principais classificações de pesquisas e especificou alguns modelos empíricos para cada categoria, sendo elas: divulgação baseada em associação, divulgação discricionária e a divulgação baseada na eficiência.

As pesquisas de divulgação baseada em associação objetivam verificar se a divulgação exógena está relacionada ou associada com variáveis de mercado, tais como análises sobre as variações no preço e no volume de venda das ações. Os estudos sobre divulgação discricionária examinam a discricionariedade dos gestores na escolha das informações divulgadas. Nessas pesquisas, a divulgação é tratada como endógena, ao contrário da categoria anterior, pois aborda fatores internos à empresa sobre a divulgação. Já as pesquisas de divulgação baseada na eficiência discutem sobre quais conjuntos de divulgações das informações são preferidos quando as informações são novas, então é verificado quais formas de divulgação é mais eficiente (VERRECCHIA, 2001).

Dye (2001) criticou os estudos sobre divulgação, principalmente o de Verrecchia (2001), e discursou sobre os pontos que concordava ou discordava. Dye (2001) concordou parcialmente sobre não haver um paradigma central sobre a divulgação e por isso ainda não poderia ser chamada de teoria, porém o autor afirma que isso serve apenas para a divulgação obrigatória, pois, para ele, a divulgação voluntária já estava mais estruturada e já era uma teoria, interligada com a teoria dos jogos.

Verrecchia (2001) afirma que os modelos exógenos e endógenos de divulgação são igualmente importantes, porém Dye (2001) discorda e aborda que os modelos endógenos são o coração da literatura sobre a divulgação. Entre as áreas abordadas por Verrecchia (2001), Dye (2001) reforça que deve ser dado mais atenção na eficiência da divulgação obrigatória, e sugere estudos para verificar justificativas eficientes para embasar a relevância da divulgação de acordo com as normas contábeis.

Verrecchia (2001) abordou a importância em verificar a influência da divulgação na redução da assimetria informacional e, consequentemente, no custo de capital das empresas, pois a assimetria inibe investimentos, o que eleva o custo para manter as operações. Nesse contexto, alguns estudos evidenciaram que a divulgação voluntária diminui a assimetria informacional (HEALY; PALEPU, 2001; LAMBERT; LEUZ; VERRECCHIA, 2007; SCOTT, 2012). Scott (2012) explica que a assimetria informacional pode ser reduzida não só com a divulgação voluntária, mas também com uma regulação mais rígida sobre as empresas.

A redução da assimetria informacional, junto com outros fatores, tais como proteção dos investidores minoritários e padronização das informações, são os principais motivos para a regulação contábil (BEAVER, 1998; CHUNG, 1999; LEV, 1988; MURCIA; SANTOS, 2009). Murcia e Santos (2009) explanam que para reduzir a assimetria com a regulação e proteger os investidores minoritários é necessário nivelar a quantidade informacional entre os investidores minoritários e majoritários, ao exigir que as empresas reportem mais informações ao mercado.

Chung (1999) afirma que a padronização contábil objetiva gerar informações contábeis de maior qualidade e diminuir a assimetria informacional. Na mesma linha de pensamento, Barth, Landsman e Lang (2008) discutem que os normatizadores objetivam agregar qualidade as práticas contábeis, aumentar a transparência e a comparabilidade dos demonstrativos, para auxiliar os investidores na alocação de seus recursos.

Conceitualmente, a regulação se caracteriza como um emaranhado de normas emitidas por entidades competentes (governo, órgãos, etc.), relacionadas à alguma atividade ou área de conhecimento, que objetiva o controle da atividade exercida (POHLMANN; ALVES; 2004). Na atividade contábil, o controle regulatório é realizado por meio de leis, normas e princípios contábeis que abordam as características de elaboração e evidenciação dos demonstrativos contábeis (LEV, 1988).

Pohlmann e Alves (2004) argumentam que o processo de normatização contábil é consequência da busca dos usuários por segurança e objetividade na elaboração das informações contábeis, principalmente num contexto em que as empresas não evidenciam, voluntariamente, informações contábeis suficientes.

A regulação influencia as informações contábeis reportadas, de forma quantitativa e qualitativa (FIELDS; LYS; VICENT, 2001). A qualidade da divulgação das demonstrações contábeis se torna uma função dos incentivos adquiridos pelos agentes, pela exigência dos usuários externos por demonstrações mais instrutiva e pela regulação (ALMEIDA, 2010).

Levitt (1998) reforça que para ter êxito, o mercado de capitais necessita de informações contábeis de qualidade e boas práticas de divulgação e que, para isso, é necessário de normas contábeis de qualidade e, assim, tornar os demonstrativos contábeis mais confiáveis ao mercado de capitais.

Nesse contexto, tem-se as normas referentes a divulgação obrigatória das informações por segmento, seja o SFAS 131, no caso das normas norte-americanas ou o IFRS 8, no caso das normas internacionais, e o CPC 22, que é a norma aplicada para as empresas brasileiras. Assim, considerando-as normas de alta qualidade, por um lado, espera-se que as empresas atendam integralmente seus requisitos, mas por outro, sabe-se que, conforme Ball, Kothari e Robin (2000), a qualidade da informação contábil não depende apenas das normas e leis, mas grandemente dos incentivos que os gestores possuem para divulgar ou deixar de divulgar uma informação.

Este estudo, ao utilizar características internas que podem influenciar no índice de divulgação das empresas, utiliza um modelo endógeno, no qual Dye (2001) explica que são os mais relevantes para a 
concretização da teoria da divulgação. Verrecchia (2001) explana a relevância na verificação da influência da divulgação na redução da assimetria informacional. Entretanto, para amenizar a assimetria, primeiramente é necessário que as empresas reportem suas informações, então esta pesquisa contribui nesse aspecto, que é o levantamento dos índices de divulgação das empresas e a identificação das características desses índices, mais especificamente quanto às informações por segmento.

\subsection{Escolhas Contábeis}

De acordo com Fields, Lys e Vincent (2001), uma escolha contábil consiste em uma decisão que tem como principal objetivo influenciar a saída do sistema contábil de uma maneira específica, não somente as demonstrações contábeis, mas também o cálculo dos impostos e assim a percepção dos órgãos reguladores.

As escolhas contábeis geralmente são relacionadas a alguns fatores referentes às imperfeições de mercado como: a assimetria informacional, que se encontra geralmente associada à relação entre gestores e investidores; a externalidades, que geralmente referem-se às relações contratuais ou não com terceiros; e os custos de agência, referentes aos aspectos contratuais como remuneração de administradores (FIELDS; LYS; VINCENT, 2001). Essas proxies delimitadas pelos autores existem devido aos contratos incompletos entre os principais e os agentes, assim como também pela ausência de um mercado perfeito (PERLINGEIRO, 2009).

Watts (1992) afirma que a escolha contábil inclui também a escolha do gestor de um método contábil em relação a outro, como é o caso da escolha do tipo de depreciação. Além disso, as escolhas contábeis incluem as escolhas realizadas por órgãos regulares como o FASB e IASB no que tange às normas contábeis por estes emitidas. Para Watts (1992), o estudo da teoria das escolhas contábeis é fundamental no estudo da contabilidade.

Bowen, Ducharme e Shores (1999) mencionam que os stakeholders utilizam a informação contábil com o objetivo de tomar decisões ou contratação e, em alguns casos, as cláusulas contratuais se fundamentam nas informações contábeis reportadas. Esses autores mencionam categorias de stakeholders que são usuários da informação contábil, tais como clientes, fornecedores, empregados, provedores de capital e reguladores.

Ainda de acordo com Bowen, Ducharme e Shores (1999), os estudos empíricos que investigaram a relação entre a tomada de decisão do investidor e as escolhas contábeis dos gestores, geralmente se deve ao fato dos incentivos de curto prazo. Dessa forma, cada stakeholder possui uma diversidade de usos da informação contábil que podem influenciar a forma com que as escolhas contábeis são realizadas.

Christie e Zimmerman (1994) evidenciam dois motivos para explicar as decisões nas escolhas contábeis, as quais são o oportunismo (se refere ao fato de que os gestores podem escolher diferentes métodos contábeis a fim de aumentar seu bem-estar à custa de outros stakeholders) e o aumento do valor da firma.

O primeiro motivo se fundamenta na intenção de os gestores em utilizarem procedimentos contábeis que melhorem o lucro afim de aumentar a remuneração por meio de planos com base em ganhos reportados e, ainda, para reduzir a probabilidade de que o gestor seja dispensado por seu baixo desempenho operacional (CHRISTIE; ZIMMERMAN, 1994).

O segundo motivo, que indica a maximização do valor da firma, é fundamentado em algumas hipóteses como: decisões a serem tomadas sobre mecanismos escolhas do método contábil; aspectos referentes a impostos; empresas que assumem o controle de outras; entre outros (CHRISTIE; ZIMMERMAN, 1994).

Watts e Zimmerman (1978) mencionam que evidenciar as características das empresas que contribuam para explicar as escolhas contábeis consiste em um dos desafios nas pesquisas nessa área e, dessa forma, essas pesquisas poderiam ser consideradas no processo de estabelecimento das normas e procedimentos contábeis.

As escolhas contábeis são essenciais no que tange as informações por segmento, pois essas informações podem diminuir a assimetria informacional, ao mesmo tempo que podem servir para relações contratuais com terceiros (clientes ou fornecedores, por exemplo). O levantamento dos índices de divulgação das empresas pode servir como evidências para a identificação das escolhas contábeis dos gestores das empresas analisadas em relação ao que é divulgado nas notas explicativas sobre as informações por segmento.

\subsection{Informação por Segmento}

De acordo com Silva, Marques e Santos (2009), a informação contábil tem passado pelo processo de normatização com o objetivo de melhorar o disclosure. Para tal, adotou-se as normas internacionais de contabilidade (IFRS) pelas empresas brasileiras. Uma delas foi o CPC 22 - Informação por segmento (baseado na IFRS 8), aprovado em 2009 e com obrigatoriedade a partir de 2010 para todas as empresas que comercializam ou que venham a comercializar seus instrumentos de dívidas ou patrimoniais no mercado de capitais brasileiro ou qualquer outro mercado organizado (ALMEIDA et al, 2015).

O CPC 22 tem como princípio básico que "a entidade deve divulgar informações que permitam aos 
usuários das demonstrações contábeis avaliarem a natureza e os efeitos financeiros das atividades de negócio nos quais está envolvida e os ambientes econômicos em que opera" (CPC, 2009, p. 1).

Almeida et al. (2015, p. 3) ressaltam que "o objetivo dessa norma é possibilitar ao investidor avaliar a natureza e os efeitos financeiros das atividades de negócio realizadas pelas empresas". Já para Fath et al. (2015), o CPC 22 assegura maior transparência aos usuários das demonstrações contábeis das empresas, pois revelam dados estratégicos pelos gestores para tomada de decisões, além de proporcionar informações financeiras de acordo com visão da gerência da empresa.

A pesquisa de Boscov (2009), feita no contexto pré emissão do CPC 22, revela que com a divulgação dessas informações poderia haver uma vinculação da contabilidade societária à contabilidade gerencial. ludícibus et al. (2010) afirmam que a lógica é que os usuários externos tenham acesso as mesmas informações que os tomadores de decisão para que possam decidir se devem ou não investir em uma determinada empresa.

Dentre os principais conceitos trazidos pelo CPC 22, destaca-se o de segmento operacional que é um componente de entidade que desenvolve atividades de negócio das quais pode obter receitas e incorrer em despesas (incluindo receitas e despesas relacionadas com transações com outros componentes da mesma entidade) e cujos resultados operacionais são regularmente revistos pelo principal gestor das operações da entidade para a tomada de decisões sobre recursos a serem alocados ao segmento e para a avaliação do seu desempenho, além da necessidade de que haja informação financeira individualizada disponível.

Ainda de acordo com o CPC 22, a expressão "principal gestor das operações" identifica uma função e não necessariamente um gestor com título específico. Essa função é o de alocar recursos e avaliar o desempenho dos segmentos operacionais da entidade. Frequentemente, o principal gestor das operações da entidade é o seu presidente ou o diretor de operações, mas pode ser, por exemplo, um grupo de diretores executivos ou outros.

O CPC 22 destaca que há determinadas exigências mínimas para divulgação dos segmentos operacionais, ou seja, nem todos os segmentos precisam ser obrigatoriamente divulgados (MACKENZIE et al., 2013). Dessa forma, um segmento operacional se torna divulgável caso atenda a um dos parâmetros mínimos quantitativos definidos no CPC 22, quais sejam:

a) Receita reconhecida, incluindo tanto as vendas para clientes externos quanto as vendas ou transferências intersegmentos, é igual ou superior a 10\% da receita combinada, interna e externa, de todos os segmentos operacionais;

b) Montante em termos absolutos do lucro ou prejuízo apurado é igual ou superior a $10 \%$ do maior, em termos absolutos, dos seguintes montantes: (i) lucro apurado combinado de todos os segmentos operacionais que não apresentaram prejuízos; e (ii) prejuízo apurado combinado de todos os segmentos operacionais que apresentaram prejuízos;

c) Seus ativos são iguais ou superiores a $10 \%$ dos ativos combinados de todos os segmentos operacionais.

Independente dos critérios estabelecidos, os segmentos operacionais que não atinjam quaisquer dos parâmetros mínimos quantitativos definidos no CPC 22 podem ser considerados divulgáveis e podem ser apresentados separadamente se a administração entender que essa informação sobre o segmento possa ser útil para os usuários das demonstrações contábeis.

Após a verificação dos parâmetros mínimos quantitativos, se o total de receitas externas reconhecido pelos segmentos operacionais representar menos de $75 \%$ da receita da entidade, segmentos operacionais adicionais devem ser identificados como segmentos divulgáveis (mesmo que eles não satisfaçam os critérios mínimos quantitativos) até que pelo menos $75 \%$ das receitas da entidade estejam incluídas nos segmentos divulgáveis.

Para empresas que possuem um único segmento operacional, o CPC 22 também exige sua divulgação, devendo evidenciar as diferentes receitas adquiridas de clientes externos dos clientes internos, assim como as receitas atreladas a clientes externos a outros países e do país-sede. Destaca-se que o CPC 22, diferente do IFRS 8, exige a divulgação das informações por região geográfica do Brasil, se forem substanciais (SILVA; PINHEIRO, 2012).

No que se refere à divulgação das informações por segmento, o CPC aborda que "a entidade deve divulgar informações que permitam aos usuários das demonstrações contábeis avaliarem a natureza e os efeitos financeiros das atividades de negócio em que está envolvida e os ambientes econômicos em que opera" (CPC, 2009, p. 5). Em outras palavras, as informações por segmentos devem ser úteis e precisas sobre a situação econômica e financeira reportadas aos investidores e credores em potencial, auxiliando-os no controle, nas avaliações e nas projeções realizadas das empresas.

\subsection{Pesquisas Anteriores}

Emmanuel e Garrod (2002) objetivaram evidenciar se as informações por segmento são relevantes e comparáveis em uma amostra de 74 empresas. Foi evidenciado que há relevância e/ou comparabilidade entre as informações por segmentos na maioria das empresas, mas em $20 \%$ delas as informações por segmento 
não apresentaram relevância e nem comparabilidade.

Vasconselos e Szuster (2003) avaliaram a qualidade dos reportes voluntários das informações por segmento no Brasil em 2001. Foi evidenciado que $57 \%$ das empresas estudadas divulgaram as informações por segmento no relatório de administração e $17 \%$ em notas explicativas, enquanto $26 \%$ não divulgaram nenhuma informação sobre seus segmentos.

Kou e Hussain (2007), com amostra de empresas europeias listadas no índice Financial Times Stock Exchange 100 (FTSE-100), verificaram que as informações por segmentos foram relatadas de forma padronizada e apresentaram alto grau de comparabilidade entre os setores industriais e as regiões geográficas.

Boscov (2009), em pesquisa na época de pré-adoção do CPC 22, identificou que a implementação da norma não seria fácil, rápida e barata, pois existiam inconsistências que gerariam problemas e afetariam a parametrização de sistemas contábeis e a comunicação entre as áreas gerenciais e financeiras. Dessa forma, houve resistências internas de implementação e necessidade de elevado detalhamento de dados, que acarretariam aumentos no preço da auditoria e da publicação das informações.

Fernandes (2009) buscou identificar diferenças nas informações por segmentos divulgadas pelas empresas petrolíferas. A autora identificou que, de modo geral, os itens divulgados atenderam as normas, pois $90 \%$ alcançaram a maior classificação em relação ao nível de aderência. A comparação das informações entre as empresas petrolíferas é consistente com a utilização tanto dos dados brutos, quanto com a mensuração de indicadores.

Talha e Salim (2010) objetivaram verificar os fatores que influenciaram a escolha das empresas em divulgar as informações por segmento de negócios ou segmento geográfico como segmento primário. Constatou-se que tamanho, desempenho financeiro e setor industrial têm significativo impacto na escolha do segmento primário como segmento de negócios em detrimento da informação geográfica.

Ferreira (2011) verificou se as informações por segmentos reduzem a assimetria informacional com relação aos riscos intrínsecos aos negócios das empresas petrolíferas. Foi concluído que as informações por área geográfica são relevantes para a tomada de decisões, pois é um critério de avaliação que pode incluir o fator risco-país e melhora o poder de avaliação do investimento.

Silva e Pinheiro (2012) evidenciaram que 63\% das 59 empresas analisadas divulgaram as informações necessárias em suas notas explicativas, mas destacaram que nenhuma companhia evidenciou todos os itens requeridos pelo CPC 22. Identificou-se ainda diferenças entre os níveis de divulgação por setor de atividade. O Ativo Total foi a única variável estatisticamente significante correlacionada com o nível de divulgação.

Schvirck, Lunkes e Gasparetto (2013) identificaram como foram definidos e quantos foram os segmentos publicados em uma amostra de 81 empresas da BM\&FBovespa. Os autores concluíram que as grandes empresas apresentam tendência de definir os segmentos com mais de um critério, provavelmente por atuarem em mercados maiores.

Kang e Gray (2013) examinaram se a adoção do IFRS 8 modificou as práticas de divulgação de informações por segmentos na Austrália. Foi evidenciado que o número médio de segmentos aumentou, porém houve pouca mudança na natureza das informações divulgadas.

Souza (2013) identificou quais os fatores que influenciam o nível de divulgação de informações sobre segmentos operacionais de empresas brasileiras. A autora verificou que as variáveis tamanho, endividamento, auditoria e governança corporativa foram estatisticamente significativas e com sinais positivos, enquanto a variável lucro ou prejuízo foi significativa, porém com sinal negativo, o que não era esperado pela autora. As variáveis rentabilidade, concentração de mercado e ano de publicação não foram determinantes do nível de divulgação.

A pesquisa de Aillón et al. (2013) teve como objetivo verificar como são demonstradas nas notas explicativas as informações gerenciais das empresas que foram divulgadas no relatório por segmento. Os achados demonstraram um nível de divulgação de $48 \%$. Também foi identificado que a variável lucro líquido é uma determinante do nível de divulgação, o que mostra que as empresas que possuem lucros divulgam mais que as empresas que possuem prejuízo. Os autores concluíram que foi encontrado um baixo de nível de evidenciação de informações gerenciais, o que pode ser justificada pela discricionariedade dos gestores na divulgação.

Souza e Sarlo Neto (2014) objetivaram identificar quais as práticas de divulgação de informações sobre segmentos operacionais apresentadas por empresas brasileiras. Os autores evidenciaram que a maioria das empresas $(86,5 \%)$ que divulgaram informações por segmentos realizaram o reporte segmentado por produtos e serviços. Também foi identificado uma baixa média de divulgação (em torno de $22 \%$ em 2010 e $24 \%$ em 2011), com um índice de divulgação máximo de $68 \%$. Os autores afirmaram que não houve uma uniformidade nas práticas de divulgação o que gerou uma baixa comparabilidade informacional entre as empresas.

Blanco, Lara e Tribó (2014) analisaram as relações causais entre ganhos de qualidade e informações por segmento. Os autores evidenciam uma relação positiva entre a qualidade e a divulgação das informações por segmento, contrapondo os argumentos de que essa relação poderia ser negativa por causa do custo de propriedade. 
Cruz et al. (2014) estudaram a formatação das notas explicativas referentes as informações por segmento das empresas brasileiras listadas no nível de governança corporativa Novo Mercado no ano de 2009. De forma geral, o reporte das informações por segmentos no Brasil estava em fases iniciais e, com isso, as empresas pouco divulgaram seus principais clientes e nenhuma divulgou o fluxo de caixa por segmento.

Weschenfelder e Mazzioni (2014) ao pesquisar o nível de evidenciação das informações por segmento nas demonstrações contábeis e quais fatores influenciam o nível de divulgação das empresas pertencentes a B3, verificaram que, devido à definição dos parâmetros de como as informações a serem evidenciadas são definidas internamente, percebeu-se um baixo índice de evidenciação. Além disso, exceto pela variável ADR, as demais não apresentaram relação significativa com o nível de evidenciação por segmentos.

Schvirck (2014) verificou se as informações por segmento das entidades que compõe o mercado de capitais brasileiro têm impacto sobre o seu desempenho. Foi identificado um reporte de demonstrações contábeis com informações por segmento em somente $43 \%$ das empresas estudadas. Também foi evidenciado que fatores como tamanho da empresa, setor de atuação e nível de governança corporativa na BM\&FBovespa, são determinantes do nível de divulgação das empresas.

Pinheiro e Boscov (2015) analisaram as informações por segmentos contidas nas notas explicativa das empresas brasileiras para identificar se as informações estão em conformidade com as exigências do CPC 22. Foi identificado que das 11 empresas da amostra (empresas premiadas pelo Troféu Transparência 2013), apenas 2 empresas tiveram índice de divulgação maior que 50\%, ou seja, as empresas estudadas possuíam baixo nível de evidenciação.

Já Souza, Schäfer e Gasparetto (2016) buscaram identificar o nível de divulgação das informações por segmento e quais variáveis influenciam o nível de divulgação. A amostra foi composta pelas empresas listadas no índice IBrX-50, abrangendo o período de 2010 a 2014 . Entre as variáveis analisadas no modelo econométrico (ativo total, endividamento, lucro líquido, setor, nível de governança e divulgação do relatório de sustentabilidade), apenas a variável endividamento foi significativa e positiva no modelo, o que indica que quanto maior o endividamento das empresas, maior é o índice de divulgação delas.

Por fim, Maier, Schäfer e Gasparetto (2017) pesquisaram o nível de divulgação de informações sobre o preço de transferência nas companhias listadas na bolsa de valores do mercado de capitais brasileiro, de acordo com as exigências dos itens 23B e 27A do CPC 22. Observou-se que 66\% das 508 empresas analisadas apresentaram informações por segmento nas notas explicativas, dentre as quais $41 \%$ (210 empresas) indicaram mais de um segmento e 10\% (49 empresas) comunicaram realizar transações entre os segmentos, sendo que apenas $2 \%$ (12 empresas) informaram não realizar transferências entre os segmentos.

De acordo com os estudos anteriores abordados, observa-se uma maior concentração de estudos qualitativos sobre níveis de divulgação considerando as normas referentes as informações por segmentos, nas quais verificam a aderência das empresas em relação as normas e a maioria dos estudos evidenciaram baixa aderência (AILLÓN et al., 2013; FERNANDES, 2009; KANG; GRAY, 2013; MAIER; SCHÄFER; GASPARETTO, 2017; PINHEIRO; BOSCOV, 2015; SCHVIRCK, 2014; SILVA; PINHEIRO, 2012; SOUZA; SCHÄFER; GASPARETTO, 2016; WESCHENFELDER; MAZZIONI, 2014). Alguns autores pesquisaram a divulgação de informações por segmento em um período onde a norma ainda não era obrigatória (CRUZ et al., 2014; VASCONSELOS; SZUSTER, 2003). Outra vertente estudada é a verificação de determinantes sobre o nível de divulgação, como ativo total, governança corporativa etc. (AILLÓN et al., 2013; SCHVIRCK; LUNKES; GASPARETTO, 2013; SILVA; PINHEIRO, 2012; SOUZA, 2013; SOUZA; SCHÄFER; GASPARETTO, 2016; TALHA; SALIM, 2010; WESCHENFELDER; MAZZIONI, 2014).

Em relação as categorias propostas por Verrecchia (2001) algumas pesquisas envolvem a questão da discricionariedade do gestor (BOSCOV, 2009), outras verificam a divulgação por segmento com a relevância e comparabilidade destas informações (EMMANUEL; GARROD, 2002; KOU; HUSSAIN, 2007) e há estudos que identificam as informações com os desempenhos internos das empresas (FERREIRA, 2011; SCHVIRCK, 2014).

Esses estudos são importantes para esta pesquisa, pois, a partir deles, foram escolhidas as principais variáveis estudadas como determinantes do nível de divulgação. Esta pesquisa se difere desses estudos em alguns aspectos importantes, tais como: inclusão de nova variável aos modelos estatístico (quantidade de segmentos reportados, segmento primário e dependência de clientes significativos), tratamento diferenciado da variável dependente (índice de divulgação), período atual, pois a maioria dos estudos, que tiveram um enfoque quantitativo associativo entre nível de divulgação e variáveis determinantes, são de antes de 2013.

Diante destes estudos e dos resultados encontrados, a pesquisa possui as seguintes hipóteses. Aillón et al. (2013), Souza, Schäfer e Gasparetto (2016) e Weschenfelder e Mazzioni (2014) não encontraram evidências de que o tamanho da empresa influencia o nível de divulgação, porém Schvirck (2014), Silva e Pinheiro (2012) e Souza (2013) identificaram uma relação positiva do ativo total da empresa com o índice de divulgação. O resultado é justificado com base no pressuposto de que quanto maior a empresa for, mais condições ela possui para sustentar os possíveis custos incorridos para informar as operações de forma segmentada. Dessa forma, a hipótese 1 da pesquisa é:

H1: Quanto maior for a empresa, em termos de ativo total, maior é o índice de divulgação. 
A variável resultado líquido tenta captar se há diferença no nível de divulgação entre as empresas que tiveram lucro e as empresas que tiveram prejuízo. Silva e Pinheiro (2012) e Souza, Schäfer e Gasparetto (2016) não verificaram relações significativas entre o resultado líquido com o nível de evidenciação. Já Aillón et al. (2013) e Souza (2013) identificaram que empresas que tiveram resultado positivo no exercício possuíram nível de evidenciação maior do que as que tiveram resultado negativo. Aillón et al. (2013) argumenta que isto pode ser um indício de que os gestores tentam omitir informações para evitar evidenciar algo que possa ligar à ineficiência da gestão. Portanto, a hipótese 2 da pesquisa é:

H2: Empresas que auferiram lucro no exercício possuem índice de divulgação maior do que as empresas que auferiram prejuízo.

A dummy governança corporativa verifica se as empresas classificadas no nível novo mercado de governança possuem diferenças em relação ao índice de divulgação em comparação com as empresas não listadas neste nível. Jensen e Meckling (1976) explanam sobre a teoria da agência e abordam que o custo com monitoramento (governança corporativa) ajuda a diminuir a assimetria informacional. Dessa forma, espera-se que as práticas de governança corporativa diminuam a assimetria informacional por meio de divulgações de mais informações aos principais (acionistas).

Aillón et al. (2013) identificaram que o nível de evidenciação não é explicado pelo nível de governança corporativa que a empresa está enquadrada. Entretanto, Schvirck (2014) e Souza (2013) encontraram uma relação positiva entre o nível de governança corporativa e o nível de evidenciação. Esses autores evidenciaram que as empresas classificadas nos níveis novo mercado, ou nível 1 ou nível 2 de governança corporativa da BM\&FBOVESPA divulgam mais que as empresas que não aderem a tais níveis. De forma complementar, Schvirck (2014) evidenciou uma discrepância no índice de divulgação em relação ao nível de governança. $O$ autor identificou que as empresas do nível 2 divulgam mais que a do nível 1 e do novo mercado, e as do nível 1 divulgam mais que as do novo mercado (N2>N1>NM). O esperado era as empresas do novo mercado divulgassem mais, já que quanto maior for as práticas de governança da empresa, maiores são as exigências sobre ela. A hipótese 3 da pesquisa é:

H3: As empresas do nível de governança Novo Mercado divulgam mais as informações sobre segmentos do que as empresas listadas em outros níveis de governanças.

Archambault e Archambault (2003) argumentaram que investidores majoritários possuem mais facilidade de obter informações diretamente da empresa e, dessa forma, grandes concentrações acionárias podem diminuir a necessidade de divulgação corporativa. Souza e Almeida (2017) pesquisaram quais fatores são relacionados com o nível de disclosure das companhias abertas brasileiras e não encontraram uma relação entre a concentração acionária e o nível de disclosure. A hipótese 4 segue o argumento de Archambault e Archambault (2003).

H4: Quanto maior for o percentual de ações ordinárias de um único investidor menor é o índice de evidenciação da empresa.

Moura, Franz e Cunha (2015) verificaram se empresas que possuem conselhos de administração mais independentes possuem melhor qualidade da informação contábil (persistência dos resultados, fluxo de caixa, conservadorismo, oportunidade, relevância). Esses autores concluíram que empresas com conselhos de administração mais independentes possuem lucros mais persistentes, oportunos e relevantes, além de serem mais conservadoras, ou seja, a independência do conselho de administração melhora a qualidade da informação contábil. Essa relação também pode ser encontrada quanto ao nível de divulgação das empresas, portanto, a hipótese 5 desta pesquisa é:

H5: Quanto mais independente for o conselho de administração da empresa, maior é o nível de evidenciação dela.

Em relação ao endividamento das empresas, espera-se que as empresas com maiores dívidas possuem um nível de divulgação maior, pois os credores necessitam estimar os fluxos de caixa da empresa para determinar a futura capacidade de pagamento, para isso eles necessitam de mais informações (SOUZA, 2013). Iatridis (2008) explica que as empresas melhoram suas publicações contábeis quando precisam de recursos, ou seja, a qualidade dessa divulgação é essencial para obter a confiança dos credores. Macagnam (2009) evidenciou uma relação positiva do endividamento com o nível de disclosure de recursos intangíveis, o que foi justificado pela autora que empresas com mais capital de terceiros necessita divulgar mais para sinalizar aos seus credores as possibilidades de lucros futuros. Em relação as informações por segmento, Souza (2013) e Souza, Schäfer e Gasparetto (2016) identificaram que quanto maior o endividamento das empresas, maior é o nível de evidenciação delas. Dessa forma, a hipótese 6 da pesquisa é:

H6: Quanto maior for o endividamento da empresa, maior é o nível de evidenciação dela.

A quantidade de segmentos que a empresa possui pode influenciar no seu índice de divulgação no momento que empresas com muitos segmentos podem possuir sistemas mais robustos para controle das informações segmentadas. Estas empresas têm uma necessidade maior de controlar de forma segmentada para auxiliar as tomadas de decisões, diferentemente das empresas com poucos segmentos, onde as informações segmentadas se assemelham com o consolidado. Assim, empresas com poucos segmentos podem não querer ter gastos maiores com implementação de um sistema mais complexo de organização das informações. Dessa forma, a hipótese 7 do estudo é:

H7: Quanto mais segmentos a empresa tiver, maior é o nível de divulgação dela. 
As empresas que possuem ADR precisam cumprir exigências tanto brasileiras, quanto americanas. Com mais exigências e mais fiscalizações as empresas tendem a divulgar mais informações por segmentos em comparação com empresas que não possuem ADR. Weschenfelder e Mazzioni (2014) reforçam que as informações por segmentos são solicitadas a mais tempo no ambiente internacional do que no Brasil, e isso pode acarretar em fiscalizações e exigências mais severas, porém em seus achados os autores identificaram uma relação negativa entre ADR e o nível de divulgação. Este resultado não era esperado pelos autores, por isso a hipótese 8 desta pesquisa é:

H8: As empresas que possuem ADR divulgam mais informações por segmento do que as empresas que não possuem ADR.

Empresas que possuem clientes significativos podem divulgar mais informações em comparação as empresas que possuem receitas pulverizadas. Isso pode ocorrer a partir do momento que estas empresas queiram ter credibilidade e confiabilidade no mercado, e assim conseguir manter seus clientes.

H9: Empresas com clientes significativos possuem um índice de divulgação maior que as empresas que possuem receitas pulverizadas.

A variável tipo de segmento são dummies que verificam se há diferenças no nível de divulgação das empresas que evidenciam as informações prioritariamente por área de negócio, ou por região geográfica, ou de ambas as formas. Empresas que possuem operações fora do Brasil precisam divulgar suas informações para outros países também, ou seja, essas empresas precisam suprir a necessidade informacional de mais usuários do que empresas que operam só no Brasil. Portanto, empresas que divulgam por região geográfica podem ter índices de divulgação maiores do que as demais empresas. Segue a hipótese 10 da pesquisa.

H10: Empresas que divulgam primariamente por região geográfica possuem o índice de divulgação maior que as empresas que divulgam por área de negócio ou de ambas as formas.

\section{Procedimentos Metodológicos}

Trata-se de uma pesquisa quali-quantitativa em que a população alvo é composta pelas empresas brasileiras de capital aberto listadas no Brasil, Bolsa, Balcão - B3 S.A (antiga BM\&FBovespa) que compõem o índice IBrX-50 no ano de 2017. O período de análise compreendeu 2010 a 2016 (sete anos) e a amostra final foi composta pelas empresas não financeiras, que divulgaram os dados necessários para as análises qualitativas e quantitativas.

As empresas do IBrX-50 foram selecionadas para a análise por sua representatividade no mercado acionário brasileiro, já que são as 50 empresas cujas ações são as mais negociadas na bolsa, ou seja, as 50 ações com maior liquidez. Trata-se de uma amostra por conveniência, pois se desejava um período amostral maior (7 anos), visando a verificação da evolução da divulgação por segmento das empresas conforme o passar dos anos, mas, por outro lado, a coleta de dados se deu de forma manual, uma limitação para se alcançar todas as empresas de capital aberto, fato que levou a limitar às empresas listadas no IBrX-50.

O Quadro 1 evidencia a composição da amostra final da análise qualitativa e quantitativa em cada ano (2010 a 2016).

\begin{tabular}{|c|c|c|c|c|c|c|c|c|}
\hline & 2010 & 2011 & 2012 & 2013 & 2014 & 2015 & 2016 & Total \\
\hline Empresas do índice IBrX-50 de 2017 & 50 & 50 & 50 & 50 & 50 & 50 & 50 & 350 \\
\hline (-) Empresas Financeiras & (9) & (9) & (9) & (9) & (9) & (9) & (9) & $(63)$ \\
\hline $\begin{array}{l}(-) \quad \text { Empresas que não } \\
\text { informações por segulgaram } \\
\text { explicativas. }\end{array}$ & (8) & (5) & (6) & (7) & (7) & (8) & $(9)$ & $(50)$ \\
\hline (-) Empresas repetidas no índice & $(2)$ & $(2)$ & $(2)$ & $(2)$ & $(2)$ & $(2)$ & $(2)$ & $(14)$ \\
\hline (=) Amostra Final Análise Qualitativa & 31 & 34 & 33 & 32 & 32 & 31 & 30 & 223 \\
\hline (-) Empresas com dados faltantes & (5) & (4) & (6) & (4) & $(2)$ & 0 & 0 & $(21)$ \\
\hline (=) Amostra Final Análise Quantitativa & 26 & 30 & 27 & 28 & 30 & 31 & 30 & 202 \\
\hline
\end{tabular}

Fonte: Elaboração própria

As empresas financeiras foram retiradas, pois na análise quantitativa a variável endividamento é analisada e como essa variável se comporta de maneira diferente para as instituições financeiras, com reflexos no cálculo do endividamento (passivo/ativo), poderia enviesar os resultados.

Algumas empresas não divulgaram informações por segmento em algum ano de análise ou então não foi possível obter informações para composição de alguma variável do modelo quantitativo. Nesses casos, as empresas foram excluídas da amostra final. A primeira parte da pesquisa consiste na análise de conteúdo das notas explicativas das demonstrações contábeis das empresas da amostra quanto às informações referentes ao CPC 22 - Informações por Segmentos. Para verificar o nível de evidenciação de cada empresa, utilizou-se um checklist baseado no trabalho de Souza (2013), que possui os requerimentos do CPC 22 sobre as informações por segmento. O checklist é composto por 7 categorias e 31 itens referentes às informações que as empresas devem divulgar. As 7 categorias são: 1) informações gerais (5 itens); 2) Informação sobre área geográfica (6 itens); 3) informação sobre produto e serviço (1 item); 4) informações sobre os principais clientes (1 item); 5 ) informações sobre lucro ou prejuízo, ativo e passivo de cada segmento 
(11 itens); 6) mensuração (2 itens); 7) conciliação (5 itens).

O primeiro passo consistiu em analisar a nota explicativa de cada empresa para identificar quais as informações sobre segmentos elas divulgaram. Para cada exigência cumprida atribui-se o valor "1", caso contrário é atribuído o valor "0". Caso algum requisito não fosse aplicável para a empresa, o item foi preenchido com N/A (não aplicável).

O segundo passo consistiu em calcular o índice de evidenciação (ID) das empresas, correspondente ao quociente entre a quantidade de itens divulgados e a quantidade de itens que deveriam divulgar. A fórmula que será utilizada é:

Em que:

$$
I D_{\text {inf } s e g}=\frac{\Sigma \text { ITENS DIVULGADOS }}{31-\Sigma \mathrm{N} / \mathrm{A}_{i}}
$$

ID $D_{\text {inf seg }}$ índice de divulgação das informações por segmento da empresa i.

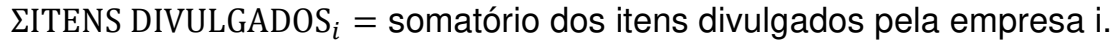

$\Sigma \mathrm{N} / \mathrm{A}_{i}=$ somatório dos itens não aplicáveis à empresa i.

A parte quantitativa da pesquisa consiste na verificação de quais características das empresas podem explicar os índices de divulgação obtidos por elas. Para tanto, utilizou-se das seguintes variáveis: ativo total, que controla o tamanho das empresas; o resultado líquido da empresa, abordada como dummy de lucro ou prejuízo; governança corporativa como dummy para as empresas listadas no nível de Governança Corporativa Novo Mercado da B3; endividamento; tipo de segmento primário da empresa; quantidade de segmentos divulgados pela empresa; existência de American Depositary Receipts (ADR); concentração acionária; independência do conselho de administração e dependência de clientes significativos.

Cabe ressaltar que a variável índice de divulgação é a variável dependente do modelo. Tendo em vista que a variável dependente apresenta valores na escala de 0 a 1, a aplicação da regressão múltipla com base nos Mínimos Quadrados Ordinários (MQO) pode trazer resultados enviesados, pois o mesmo assume que a variável dependente seja contínua. Dessa forma, para que a regressão MQO não produzisse resultados enviesados, foi adotado o procedimento proposto por Fávero et al. (2009), que multiplica a variável por 100, permitindo que a variável tenha valores fora da faixa de 0 a 1 exclusivamente.

As características das empresas foram obtidas com base na literatura precedente. A descrição das mesmas, fórmulas de cálculo e referência são apresentadas no Quadro 2.

Quadro 2: Variáveis, Fórmulas e Fundamentações

\begin{tabular}{|c|c|c|}
\hline Variáveis & Operacionalização & Referência \\
\hline $\begin{array}{l}\text { Tamanho - } \\
\text { Logaritmo } \\
\text { Natural do Ativo } \\
\text { Total }\end{array}$ & LN(AT) & $\begin{array}{c}\text { Aillón et al. (2013); Schvirck (2014); Silva } \\
\text { e Pinheiro (2012); Souza (2013); Souza, } \\
\text { Schäfer e Gasparetto (2016); } \\
\text { Weschenfelder e Mazzioni (2014) }\end{array}$ \\
\hline $\begin{array}{l}\text { Resultado } \\
\text { Líquido }\end{array}$ & $\begin{array}{l}1 \text { - Se teve lucro no exercício } \\
0 \text { - Se teve prejuízo no exercício }\end{array}$ & $\begin{array}{c}\text { Aillón et al. (2013); Silva e Pinheiro (2012); } \\
\text { Souza (2013); Souza, Schäfer e } \\
\text { Gasparetto (2016) }\end{array}$ \\
\hline $\begin{array}{l}\text { Governança- } \\
\text { Novo Mercado }\end{array}$ & $\begin{array}{l}1 \text { - Se pertencer ao Novo Mercado } \\
0 \text { - Se não pertencer ao Novo Mercado }\end{array}$ & $\begin{array}{l}\text { Aillón et al. (2013); Schvirck (2014); Souza } \\
\text { (2013) }\end{array}$ \\
\hline Endividamento & $\frac{\text { Capital de Terceitos (Passivo) }}{\text { Ativo Total }}$ & $\begin{array}{c}\text { Souza (2013); Souza, Schäfer e } \\
\text { Gasparetto (2016); Weschenfelder e } \\
\text { Mazzioni (2014) }\end{array}$ \\
\hline \multirow{2}{*}{$\begin{array}{l}\text { Tipo de } \\
\text { Segmento } \\
\text { Primário }\end{array}$} & $\begin{array}{l}1 \text { - Segmento primário por área de negócio } \\
0 \text { - Segmento primário por região geográfica ou de } \\
\text { forma misturada }\end{array}$ & ( \\
\hline & $\begin{array}{l}1 \text { - Segmento primário por área região geográfica } \\
0 \text { - Segmento primário por área de negócio ou de } \\
\text { forma misturada }\end{array}$ & - \\
\hline $\begin{array}{l}\text { Quantidade de } \\
\text { Segmentos } \\
\text { Reportados }\end{array}$ & $\begin{array}{c}\text { Quantidade de segmentos reportados pela } \\
\text { empresa }\end{array}$ & - \\
\hline ADR & $\begin{array}{l}1 \text { - Se a empresa possui ADR } \\
0 \text { - Se a empresa não possui ADR }\end{array}$ & Weschenfelder e Mazzioni (2014) \\
\hline $\begin{array}{l}\text { Concentração } \\
\text { Acionária }\end{array}$ & $\begin{array}{c}\text { Percentual de ações do acionista que possui a } \\
\text { maior quantidade de ações ordinárias }\end{array}$ & Schvirck (2014); Souza e Almeida (2017) \\
\hline $\begin{array}{l}\text { Independência } \\
\text { do Conselho de } \\
\text { Administração }\end{array}$ & $\frac{\text { Quantidade de Conselheiros Independentes }}{\text { Total de Conselheiros }}$ & $\begin{array}{l}\text { Schvirck, Lunkes e Gasparetto (2013); } \\
\text { Moura, Franz e Cunha (2015) }\end{array}$ \\
\hline $\begin{array}{l}\text { Dependência de } \\
\text { Clientes } \\
\text { Significativos }\end{array}$ & $\begin{array}{l}1 \text { - Se a empresa possui clientes significativos } \\
0 \text { - Se a empresa não possui clientes significativos }\end{array}$ & - \\
\hline
\end{tabular}

Fonte: Elaboração própria 
Ressalta-se que para representar o tipo de segmento primário reportado pela empresa foram constituídas duas dummys, pois há três categorias: 1) empresas que divulgam de forma primária por área de negócio, que assume valor 1 na primeira dummy e valor 0 na segunda; 2) empresas que divulgam de forma primária por região geográfica, que assume valor 0 na primeira dummy e valor 1 na segunda; 3 ) empresas que divulgam de forma misturada, pois possuem segmentos reportados tanto por região geográfica, quanto por área de negócio, que assume o valor 0 nas duas dummys, ou seja, é a categoria de controle capturada pelo intercepto da regressão.

Para verificar quais características das empresas influenciam o índice de divulgação foi utilizado o modelo de regressão com base no MQO, apresentado a seguir.

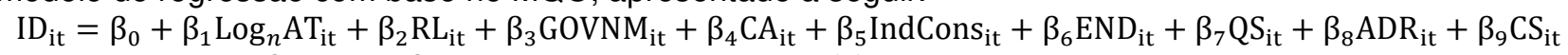

Em que:

$$
+\beta_{10} \mathrm{RG}_{\mathrm{it}}+\beta_{11} \mathrm{AN}_{\mathrm{it}}+\varepsilon_{\mathrm{it}}
$$

IDit = índice de divulgação das informações por segmento da empresa i, no ano t, multiplicado por 100;

$\log _{n} A T_{\text {it }}=$ logaritmo natural do ativo total da empresa $\mathrm{i}$, no ano $\mathrm{t}$;

$\mathrm{R} \mathrm{L}_{\mathrm{it}}=$ dummy de resultado líquido da empresa $\mathrm{i}$, no ano $\mathrm{t}$, na qual assume o valor 1 se a empresa teve lucro no exercício e 0 , caso contrário;

$\mathrm{GOVNM}_{\mathrm{it}}=$ dummy de governança corporativa da empresa i, no ano t, na qual assume valor 1 se a empresa for do nível novo mercado de governança corporativa da bolsa de valores e 0 , caso contrário;

$\mathrm{CA}_{\text {it }}=$ concentração de ações do acionista controlador;

IndCosit = quantidade de Conselheiros Independentes divulgados nos formulários de referência ou relatório anual da empresa i dividido pelo total de Conselheiros divulgados nos formulários de referência da empresa i;

$E N D_{\text {it }}=$ endividamento da empresa $\mathrm{i}$, no ano $\mathrm{t}$;

QS it = quantidade de segmentos divulgados em suas notas explicativas da empresa $\mathrm{i}$, no ano $\mathrm{t}$;

$A D R_{i t}=$ dummy se a empresa $i$, no ano $t$, na qual assume $o$ valor 1 se a empresa possui $A D R$ e 0 se a empresa não possui ADR;

$C S_{i t}=$ dummy da empresa $\mathrm{i}$, no ano $\mathrm{t}$, na qual assume o valor 1 se a empresa possui clientes significativos e 0 se a empresa não possui clientes significativos.

$R G_{i t}=$ dummy de segmento primário da empresa $\mathrm{i}$, no ano $\mathrm{t}$, na qual assume o valor 1 se a empresa divulga primeiramente por região geográfica e 0 se opta divulgar por área de negócio ou de forma misturada;

$N A_{i t}=$ dummy de segmento primário da empresa $\mathrm{i}$, no ano $\mathrm{t}$, na qual assume o valor 1 se a empresa divulga primeiramente por Área de Negócio e 0 se opta divulgar por região geográfica ou de forma misturada;

$\varepsilon_{\text {it }}=$ erro da regressão;

$\beta=$ coeficientes lineares e angulares da regressão.

As informações necessárias de cada variável independente foram coletadas da seguinte forma:

Economática®;

a) Ativo Total ( $\left.\log _{n} A T_{i t}\right)$; Resultado Líquido (RL $\mathrm{L}_{\mathrm{it}}$ ); Governança Corporativa (GOVNM $\mathrm{G}_{\mathrm{it}}$ ):

d) Concentração Acionária ( $\left.C A_{i t}\right)$ : formulário de referência no site da CVM, no item 15 - controle;

e) Independência do Conselho de Administração (IndCosit): ou no formulário de referência no site da CVM, no item 12 - Assembleia e Administração, ou nos relatórios anuais nos sites das empresas. Em raras situações as informações estavam em outros relatórios, como o de Sustentabilidade;

f) Endividamento (ENDit): calculada no Excel. As variáveis utilizadas para o cálculo (ativo e passivo) foram retiradas da Economática®;

g) Quantidade de Segmentos (QS it); Clientes Significativos (CS it); Região Geográfica ou Área de Negócio (RG $\mathrm{it}_{\mathrm{t}}$ e $N \mathrm{~A}_{\mathrm{it}}$ ): notas explicativas das empresas, no item referente as informações por segmentos; empresas;

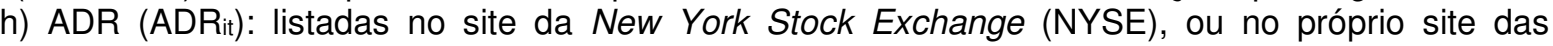

O modelo de regressão foi gerado por mínimo quadrado ordinário (MQO), de forma empilhada, pois os dados não estão organizados em painel balanceado. A regressão foi executada no sistema estatístico Gretl.

De acordo com Fávero et al. (2009), a regressão por MQO precisa ser validada e, para isso, deve-se testar os pressupostos da normalidade dos resíduos, da homocedasticidade dos resíduos e da colinearidade das variáveis explicativas. A normalidade dos resíduos foi verificada pelo teste Qui-quadrado. A homocedasticidade dos resíduos foi identificada pelo teste de White. A colinearidade dos regressores foi evidenciada pelo fator de inflação da variância (FIV).

Gujarati e Porter (2011) explicam que deve ser realizado o teste $\mathrm{F}$ para verificar a robustez do modelo como um todo. Se o teste $\mathrm{F}$ for significante evidencia que há pelo menos uma variável independente que explica a variável dependente, dessa forma é necessário realizar o teste t para averiguar quais variáveis explicativas possuem relação linear com a variável dependente.

As principais limitações deste estudo são relacionadas à amostra final, à coleta e ao tratamento dos dados. As empresas analisadas foram selecionadas a partir do índice IBrX-50 da BM\&FBovespa, que é apenas um extrato de todas as empresas listada na bolsa. Foram retiradas as empresas que não possuíram 
dados necessários para a análise e as empresas financeiras. Dessa forma, a amostra final foi composta de forma não aleatória, então os resultados não podem gerar inferências para as outras empresas que não fazem parte da amostra.

\section{Resultados}

Os resultados estão divididos em duas partes, a primeira é a análise qualitativa dos índices de divulgação, e a segunda é a análise quantitativa dos determinantes do índice de divulgação das empresas.

\subsection{Análise Qualitativa}

A análise qualitativa tem como foco a evidenciação dos índices de divulgação de cada empresa em cada ano de análise (2010 a 2016), da média total de cada empresa (média aritmética de cada empresa nos 7 anos de análise), e a média anual de todas as empresas (média aritmética anual das 34 empresas).

O quadro 3 evidencia os índices de divulgação por empresa e as médias totais e anuais. O quadro está organizado de forma decrescente da média total de cada empresa. Os espaços em brancos indicam que a empresa não divulgou informações por segmento no ano.

Quadro 3: Índice de Divulgação por Empresa e Média Geral

\begin{tabular}{|c|c|c|c|c|c|c|c|c|}
\hline \multirow{2}{*}{ Empresas } & \multicolumn{7}{|c|}{ ID ANUAL } & \multirow{2}{*}{ MÉDIA ID } \\
\hline & 2010 & 2011 & 2012 & 2013 & 2014 & 2015 & 2016 & \\
\hline Cosan & $71,43 \%$ & $73,33 \%$ & $87,10 \%$ & $93,55 \%$ & $93,55 \%$ & $93,33 \%$ & $93,55 \%$ & $86,55 \%$ \\
\hline Lojas Americanas & $80,77 \%$ & $80,77 \%$ & $80,77 \%$ & $80,77 \%$ & $80,77 \%$ & $80,77 \%$ & $80,77 \%$ & $80,77 \%$ \\
\hline CCR & $78,57 \%$ & $78,57 \%$ & $75,86 \%$ & $78,57 \%$ & $78,57 \%$ & $78,57 \%$ & $78,57 \%$ & $78,18 \%$ \\
\hline Ecorodovias & & $64,00 \%$ & $84,62 \%$ & $84,62 \%$ & $80,77 \%$ & $64,00 \%$ & $64,00 \%$ & $73,67 \%$ \\
\hline Gerdau & $75,00 \%$ & $75,00 \%$ & $71,43 \%$ & $72,41 \%$ & $72,41 \%$ & $72,41 \%$ & $72,41 \%$ & $73,01 \%$ \\
\hline Natura & $72,41 \%$ & $72,41 \%$ & $72,41 \%$ & $72,41 \%$ & $72,41 \%$ & $72,41 \%$ & $72,41 \%$ & $72,41 \%$ \\
\hline Ambev & $71,43 \%$ & $71,43 \%$ & $71,43 \%$ & $72,41 \%$ & $72,41 \%$ & $72,41 \%$ & $72,41 \%$ & $71,99 \%$ \\
\hline MRV & & $69,23 \%$ & $72,00 \%$ & & & & & $70,62 \%$ \\
\hline Equatorial & - & $69,23 \%$ & $69,23 \%$ & $69,23 \%$ & $69,23 \%$ & $69,23 \%$ & $69,23 \%$ & $69,23 \%$ \\
\hline Cemig & $53,85 \%$ & $74,07 \%$ & $74,07 \%$ & $70,37 \%$ & $70,37 \%$ & $70,37 \%$ & $70,37 \%$ & $69,07 \%$ \\
\hline Localiza & $60,71 \%$ & $67,86 \%$ & $67,86 \%$ & $67,86 \%$ & $67,86 \%$ & $67,86 \%$ & $67,86 \%$ & $66,84 \%$ \\
\hline Pão de Açúcar & $60,71 \%$ & $64,29 \%$ & $64,29 \%$ & $64,29 \%$ & $64,29 \%$ & $75,00 \%$ & $72,00 \%$ & $66,41 \%$ \\
\hline Klabin & $62,07 \%$ & $65,52 \%$ & $65,52 \%$ & $65,52 \%$ & $65,52 \%$ & $65,52 \%$ & $65,52 \%$ & $65,02 \%$ \\
\hline Petrobras & $65,52 \%$ & $65,52 \%$ & $65,52 \%$ & $65,52 \%$ & $66,67 \%$ & $63,33 \%$ & $56,67 \%$ & $64,11 \%$ \\
\hline Braskem & $53,33 \%$ & $61,29 \%$ & $61,29 \%$ & $61,29 \%$ & $60,00 \%$ & $66,67 \%$ & $64,52 \%$ & $61,20 \%$ \\
\hline Embraer & $60,71 \%$ & $60,71 \%$ & $60,71 \%$ & $60,71 \%$ & $60,71 \%$ & $60,71 \%$ & $60,71 \%$ & $60,71 \%$ \\
\hline Vale & $58,62 \%$ & $58,62 \%$ & $58,62 \%$ & $58,62 \%$ & $58,62 \%$ & $58,62 \%$ & $65,52 \%$ & $59,61 \%$ \\
\hline Weg & $57,14 \%$ & $57,14 \%$ & $57,14 \%$ & $57,14 \%$ & $57,14 \%$ & $57,14 \%$ & $57,14 \%$ & $57,14 \%$ \\
\hline Ultrapar & $55,17 \%$ & $55,17 \%$ & $55,17 \%$ & $55,17 \%$ & $58,62 \%$ & $58,62 \%$ & $60,00 \%$ & $56,85 \%$ \\
\hline Usiminas & $53,57 \%$ & $53,57 \%$ & $53,57 \%$ & $50,00 \%$ & $50,00 \%$ & $50,00 \%$ & $75,00 \%$ & $55,10 \%$ \\
\hline Qualicorp & $53,85 \%$ & $53,85 \%$ & $53,85 \%$ & $53,85 \%$ & $53,85 \%$ & $53,85 \%$ & $53,85 \%$ & $53,85 \%$ \\
\hline Sabesp & $52,17 \%$ & $50,00 \%$ & $50,00 \%$ & $54,55 \%$ & $54,55 \%$ & $54,55 \%$ & $60,00 \%$ & $53,69 \%$ \\
\hline Suzano & $50,00 \%$ & $46,43 \%$ & $51,72 \%$ & $50,00 \%$ & $53,57 \%$ & $53,57 \%$ & $64,29 \%$ & $52,80 \%$ \\
\hline Multiplan & $46,15 \%$ & $46,15 \%$ & $46,15 \%$ & $48,15 \%$ & $48,15 \%$ & $48,15 \%$ & $48,15 \%$ & $47,29 \%$ \\
\hline JBS & $44,83 \%$ & $44,83 \%$ & $44,83 \%$ & $44,83 \%$ & $44,83 \%$ & $44,83 \%$ & $44,83 \%$ & $44,83 \%$ \\
\hline Kroton & $44,00 \%$ & $44,00 \%$ & $44,00 \%$ & $44,00 \%$ & $44,00 \%$ & $44,00 \%$ & $44,00 \%$ & $44,00 \%$ \\
\hline BRF & $43,33 \%$ & $41,38 \%$ & $41,38 \%$ & $41,38 \%$ & $43,33 \%$ & $43,33 \%$ & $43,33 \%$ & $42,50 \%$ \\
\hline Eletrobrás & $40,00 \%$ & $36,00 \%$ & $36,00 \%$ & $36,00 \%$ & $38,46 \%$ & $48,00 \%$ & $52,00 \%$ & $40,92 \%$ \\
\hline Br Malls & $34,78 \%$ & $34,78 \%$ & $41,67 \%$ & $41,67 \%$ & $41,67 \%$ & $41,67 \%$ & $41,67 \%$ & $39,70 \%$ \\
\hline Fibria & $39,29 \%$ & $39,29 \%$ & & & & & - & $39,29 \%$ \\
\hline Siderúrgica & $35,71 \%$ & $35,71 \%$ & $35,71 \%$ & $35,71 \%$ & $35,71 \%$ & $35,71 \%$ & - & $35,71 \%$ \\
\hline Lojas Renn & $24,00 \%$ & $24,00 \%$ & $36,00 \%$ & $36,00 \%$ & $36,00 \%$ & $44,00 \%$ & $44,00 \%$ & $34,86 \%$ \\
\hline Rumo & $27,59 \%$ & $27,59 \%$ & $28,57 \%$ & $26,92 \%$ & $55,56 \%$ & $33,33 \%$ & $42,31 \%$ & $34,55 \%$ \\
\hline Hypermarcas & $29,63 \%$ & $27,59 \%$ & $28,57 \%$ & $28,57 \%$ & $28,57 \%$ & & & $28,59 \%$ \\
\hline Média Anual & $53,43 \%$ & $55,57 \%$ & $57,79 \%$ & $57,57 \%$ & $58,69 \%$ & $59,42 \%$ & $61,90 \%$ & $57,72 \%$ \\
\hline
\end{tabular}

Fonte: Dados da pesquisa.

Ao analisar o Quadro 3, observa-se que nenhuma empresa em nenhum dos anos atingiu índice de divulgação de $100 \%$. Silva e Pinheiro (2012) também evidenciaram que das 59 empresas da amostra, nenhuma delas divulgaram todos os itens solicitados.

A empresa com maior índice de divulgação em um determinado ano é a Cosan, com ID de 93,55\% nos anos de 2013, 2014 e 2016. A Cosan também possui a maior média de ID total, com $86,55 \%$, na frente das Lojas Americanas com um ID médio de $80,77 \%$ e da CCR com 78,18\%. Essas três empresas citadas são as que apresentaram os maiores ID médio. 
Por outro lado, verifica-se que o menor ID médio é da Hypermarcas, com 28,59\%. Entretanto, o menor ID em um determinado ano é da companhia Lojas Renner nos anos de 2010 e 2011 (24\%). A Hypermarcas é a única empresa na faixa de $20 \%$ a $30 \%$, abaixo das empresas Rumo (34,55\%), Lojas Renner (34,86\%), Siderúrgica Nacional (35,71\%), Fibria (39,29\%) e Br Malls (39,70\%), que são as empresas na faixa de $30 \%$ a $40 \%$.

O índice de divulgação médio total de todas as empresas é de 57,72\%, o que significa que as empresas estudadas divulgam em média 57,72\% das informações por segmento solicitadas pelo CPC 22. Entretanto, percebe-se uma alta variação no ID, no qual o menor ID é de $28,59 \%$ e o maior é de $86,55 \%$.

Aillón et al. (2013) encontrou nível de divulgação de 48\% para as empresas que faziam parte do IBrX50 no ano de 2010. Observa-se no Quadro 3 que o ID médio das 34 empresas no ano de 2010 (53,43\%) ficou bem próximo ao encontrado por Aillón et al. (2013). Não são exatamente as mesmas empresas, mas estes índices de divulgação mostram que as empresas divulgavam basicamente metade das informações solicitadas pelo CPC 22 no início da sua vigência. Pinheiro e Boscov (2015) também verificaram um baixo índice de divulgação nas 11 empresas analisadas, nas quais apenas 2 tiveram um ID maior que $50 \%$.

Em uma análise dos índices de divulgação de cada empresa de um ano para o outro, é possível observar que as empresas Lojas Americanas, Natura, Equatorial, Embraer, WEG, Qualicorp, Kroton, JBS e Fibria mantiveram seus ID de 2010 em todos os outros anos. Esses casos podem refletir as situações em que há uma formatação padrão das notas explicativas utilizadas em todos os anos sem a preocupação de revisão destas informações, se são suficientes ou não.

De forma parecida com as empresas citadas anteriormente, as companhias CCR, Localiza, Klabin e Vale tiveram seus ID's anuais praticamente iguais, de um ano para o outro, com apenas um desses anos sendo diferente dos demais.

Os destaques negativos são a Gerdau, a Petrobras e a Hypermarcas, que foram as únicas três empresas que tiveram queda no índice de divulgação ao comparar o ID de 2010 com o de 2016. A Petrobras teve um ID de 65,52\% em 2010 e 56,67\% em 2016, um decréscimo de quase 9\%. Esta queda no ID é proveniente da redução da divulgação das informações sobre área geográfica (categoria 2), em que a empresa divulgava 50\% de 2010 a 2014, mas reduziu para 33,33\% em 2015 e 0\% em 2016.

A redução do ID da Gerdau está relacionada à categoria 5 (informações de lucro, prejuízo, ativo e passivo de cada segmento), pois a empresa divulgava 100\% das informações requeridas nos anos de 2010 e 2011, mas passou a divulgar 90,91\% nos demais anos.

Já a Hypermarcas, a redução do ID foi causada pelo menor reporte sobre as informações gerais dos segmentos da empresa (categoria 1), pois em 2010 houve um reporte de $75 \%$ das informações gerais que diminuiu para $60 \%$ a partir de 2011.

As empresas que tiveram as maiores variações positivas no ID foram a Cosan, Usiminas e Lojas Renner, com aumentos de 22,12\%, 21,43\% e 20,00\%, respectivamente, ao se comparar 2010 com 2016 . As demais empresas tiveram, predominantemente, acréscimo em seus índices de divulgação ao longo do tempo. Essa melhora pode ser evidenciada pela média anual de todas as empresas: 2010 (53,43\%), 2011 (55,57\%), 2012 (57,79\%), 2013 (57,57\%), 2014 (58,69\%), 2015 (59,42\%), 2016 (61,90\%). De 2010 a 2016 calcula-se um aumento de $8,47 \%$ no índice de divulgação médio das empresas.

\subsection{Análise Quantitativa}

A análise quantitativa está dividida em três partes gerais: visualização breve da estatística descritiva das variáveis; análise dos pressupostos, $\mathrm{R}^{2}$ e teste $\mathrm{F}$, para validar a regressão; e a análise da significância de cada variável, rejeição ou não das hipóteses e comparações com os estudos anteriores. Primeiramente, segue o Quadro 4 com as informações sobre a média, o desvio padrão, mínimo e máximo das variáveis que possuem métricas escalares. As variáveis dummies, como são variáveis nominais o Quadro 4 mostra apenas o percentual de observações que assumiram o valor 1 ou o valor 0 .

\begin{tabular}{|c|c|c|c|c|}
\hline Variáveis Escalares & Média & Desvio Padrão & Mínimo & Máximo \\
\hline Índice de Divulgação & 57,570 & 15,480 & 24,000 & 93,540 \\
\hline Ln Ativo & 16,834 & 1,174 & 13,906 & 20,618 \\
\hline Concentração Acionária & 0,3815 & 0,232 & 0,050 & 1,000 \\
\hline Independência do Conselho & 0,360 & 0,192 & 0,090 & 0,875 \\
\hline Endividamento & 0,633 & 0,152 & 0,213 & 0,966 \\
\hline Quantidade de Segmentos & 3,610 & 1,210 & 1 & 7 \\
\hline Variáveis Dummys & \multicolumn{2}{|c|}{$\%$ de observações 1} & \multicolumn{2}{|c|}{ \% de observações 0} \\
\hline Resultado Líquido & \multicolumn{2}{|c|}{$84,15 \%$} & \multicolumn{2}{|c|}{$15,85 \%$} \\
\hline Governança Corporativa & \multicolumn{2}{|c|}{$65,35 \%$} & \multicolumn{2}{|c|}{$34,65 \%$} \\
\hline ADR & \multicolumn{2}{|c|}{$51,98 \%$} & \multicolumn{2}{|c|}{$48,02 \%$} \\
\hline Região Geográfica & \multicolumn{2}{|c|}{$12,87 \%$} & \multicolumn{2}{|c|}{$87,13 \%$} \\
\hline Área de Negócio & \multicolumn{2}{|c|}{$79,20 \%$} & \multicolumn{2}{|c|}{$20,80 \%$} \\
\hline
\end{tabular}

Fonte: Dados da Pesquisa. 
A variável índice de divulgação possui média de 57,57\%, um pouco diferente da média de $57,72 \%$ evidenciado na análise qualitativa. Essa discrepância é proveniente de quantidade de empresas analisadas, pois a qualitativa totalizou 220 e a quantitativa foram 202.

A média da concentração acionária indica que em torno de $38 \%$ das ações ordinárias das empresas estão em controle de um único acionista. O mínimo encontrado foi de $5 \%$ da empresa Br Malls e da Kroton. Entre todas as empresas, a Br Malls possui a menor média de concentração acionária de 2010 a 2016, ou seja, é a empresa que possui suas ações mais difundidas no mercado.

Da totalidade de membros do conselho de administração, as empresas possuem em média $36 \%$ de conselheiros independentes. Este percentual está acima do percentual proposto para as práticas de governança corporativa listadas no Novo Mercado e Nível 2, que é de $20 \%$. O nível de governança corporativa Nível 1 não apresenta requisitos mínimos em relação a quantidade de conselheiros.

A composição mínima de conselheiros independentes é de $9 \%$, que é da empresa Vale em todos os anos de análise (2010 a 2016). A Vale está listada no Nível 1 de governança, ou seja, não há exigência de um mínimo, porém há empresas listadas no Novo Mercado ou Nível 2 que possuem menos de $20 \%$ de conselheiros independentes, a exemplo da Multiplan (Nível 2), que apresentou percentual de $14 \%$ de conselheiros independentes de 2010 a 2016.

Em algumas empresas, a maior parte dos conselheiros administrativos são independentes. Destaque para as Lojas Renner que em 2015 e 2016 possuíam 88\% de independência do seu conselho administrativo.

Em relação a quantidade de segmentos, observa-se que as empresas divulgam em média de 3 a 4 segmentos. Das 202 observações analisadas, 125 relataram 3 ou 4 segmentos. O máximo de 7 segmentos pertence a Petrobras, que juntamente com a Cosan e BRF são as empresas que possuem mais segmentos (6 a 7 segmentos).

Das variáveis dummies, destaca-se o percentual das empresas listadas no Novo Mercado (65,35\%), o que indica, teoricamente, que a maioria das empresas estão classificadas nas melhores práticas de governança corporativa. O percentual mais equilibrado é da dummy ADR. Praticamente metade das empresas analisadas possuem ADR, enquanto que a outra metade não. Outro destaque é o reporte por segmento primário por área de negócio das empresas $(79,20 \%)$, em detrimento da divulgação primária por região geográfica (12,87\%).

O segundo passo da análise quantitativa é a verificação se a regressão é válida como um todo e o levantamento dos pressupostos da regressão para identificar se a regressão possa estar enviesada ou não. A Tabela 1 evidencia o $R^{2}$ do modelo, os $p$-valores do teste $F$, do teste de White para a heterocedasticidade, do teste Qui-quadrado para normalidade, e o Fator de Inflação da variância (FIV) de cada variável.

Tabela 1 - Pressupostos, Teste F e R ${ }^{2}$

\begin{tabular}{l|c|l}
\hline \multicolumn{1}{c}{ Variáveis } & FIV & P-Valores, Hipóteses do Teste e R ${ }^{2}$ \\
\hline LN Ativo Total & 2,661 & Teste de White: <0,0001 \\
Resultado Líquido & 1,202 & \\
Governança Corporativa & 1,660 & H0: Resíduos Homocedásticos \\
Concentração Acionária & 1,544 & $\mathrm{H} 1:$ Resíduos Heterocedásticos \\
\cline { 3 - 3 } Independência do Conselho & 1,436 & Teste Qui-quadrado: 0,00890428 \\
Endividamento & 1,274 & $\mathrm{H} 0:$ Resíduos Normais \\
Quantidade de Segmentos & 1,567 & $\mathrm{H} 1:$ Resíduos Não Normais \\
\cline { 3 - 3 } ADR & 2,124 & Teste (F): <0,0001 \\
Clientes Significativos & 1,223 & $\mathrm{H} 0: \mathrm{R}^{2}=0$ \\
Área de Negócio & 2,697 & $\mathrm{H} 1: \mathrm{R}^{2}>0$ \\
\cline { 3 - 3 } Região Geográfica & 2,780 & $\mathrm{R}^{2}: 0,387672$ \\
\hline
\end{tabular}

Fonte: Dados da pesquisa

O $R^{2}$ da regressão é de $38,76 \%$, que é o poder explicativo, ou seja, as variações nas variáveis independentes explicam 38,76\% da variação do índice de divulgação. Como os testes estatísticos trabalham com faixas de valores, o teste $(F)$ verifica se este $R^{2}$ pode ser considerado zero ou se o valor encontrado é real. $O$ p-valor do teste $(F)$ é de $<0,0001$ menor que o nível de significância aceito nesta pesquisa $(0,1)$, então a hipótese nula é rejeitada para a aceitação da hipótese alternativa, que indica o $R^{2}$ é real. Dessa forma, a regressão é válida como um todo e há pelo menos uma variável significativa no modelo que explica o índice de divulgação.

O p-valor do teste Qui-quadrado para verificar a normalidade dos resíduos é de 0,00890428, então a hipótese alternativa é aceita, o que evidencia que os resíduos não são normais. Stevenson (1981) explica que de acordo com o teorema do limite central quando os modelos possuem mais de 30 observações os dados tendem a normalidade. Esta regressão possui 202 observações, optando-se por relaxar o pressuposto da normalidade.

O p-valor do teste de White para a heterocedasticidade dos resíduos é de $<0,0001$, também menor 
que o nível de significância, o que indica que os resíduos são heterocedásticos, ou seja, possuem variâncias diferentes. Dessa forma, os resultados obtidos na regressão foram corrigidos utilizando-se erros padrão robustos.

Por último, de acordo com o fator de inflação da variância (FIV) de cada variável, percebe-se que o maior FIV é de 2,780 da variável dummy Região Geográfica. Fávero et al. (2009) mostram que se o FIV for maior que 10 há fortes indícios de problema de colinearidade entre as variáveis independentes, que indica uma correlação entre estas variáveis. Observa-se, então, que todas as variáveis possuem FIV menor que 10, que indica não haver problema de colinearidade entre elas.

Os pressupostos indicam que a regressão não está enviesada e o teste $\mathrm{F}$ indica que a regressão é válida como um todo e que há pelo menos uma variável independente que explica o índice de divulgação. Portanto, o próximo passo foi analisar a regressão em si para saber quais variáveis foram significativas no modelo e que explicam o ID.

É evidenciado na Tabela 2 quais variáveis são significativas ou não no modelo. Das 11 variáveis do modelo, 8 foram estatisticamente significantes, nas quais seis variáveis apresentam significância a 1\% ( $L n$ Ativo Total, Resultado Líquido, Concentração Acionária, Endividamento, Quantidade de Segmentos e Clientes Significativos), duas significativas a 5\% (Governança Corporativa e Região Geográfica) e uma a 10\% (Área de Negócio).

\begin{tabular}{l|c|c|c|c}
\multicolumn{5}{c}{ Tabela 2 - Regressão Pooled por Erros Padrão Robustos (202 observações) } \\
\hline \multicolumn{1}{c}{ Variáveis } & Coeficiente & Erro Padrão & razão-t & p-valor \\
\hline Constante & 52,14020 & 18,82650 & 2,7695 & $0,00617^{* * *}$ \\
Ln Ativo Total & $-2,95283$ & 1,13288 & $-2,6065$ & $0,00987^{* * *}$ \\
Resultado Líquido & 7,65015 & 2,49904 & 3,0612 & $0,00252^{* * *}$ \\
Governança Corporativa & $-5,25639$ & 2,49324 & $-2,1083$ & $0,036322^{* *}$ \\
Concentração Acionária & 15,76480 & 4,72796 & 3,3344 & $0,00103^{* * *}$ \\
Independência do Conselho & 2,74590 & 5,67964 & 0,4835 & 0,62932 \\
Endividamento & 40,43620 & 6,31426 & 6,4039 & $<0,00001^{* * *}$ \\
Quantidade de Segmentos & 2,77669 & 0,90829 & 3,0571 & $0,00256^{* * *}$ \\
ADR & 2,53894 & 2,59796 & 0,9773 & 0,32967 \\
Clientes Significativos & 9,94795 & 2,66990 & 3,7260 & $0,00026^{* * *}$ \\
Área de Negócio & 6,90842 & 4,09615 & 1,6866 & $0,09333^{*}$ \\
Região Geográfica & 12,27500 & 4,86370 & 2,5238 & $0,01243^{* *}$ \\
\hline
\end{tabular}

Fonte: Dados da pesquisa.

Nota: Significância estatística a *** $1 \%$ ** $5 \%$ * $10 \%$.

O logaritmo natural do ativo, que representa o tamanho da empresa, foi significativo a $1 \%$, porém a relação encontrada entre essa variável com o ID foi negativa, ao contrário do esperado na hipótese 1. Este resultado vai contra aos achados de Schvirck (2014), Silva e Pinheiro (2012) e Souza (2013), que identificaram relação positiva.

Estes autores justificaram que quanto maior a empresa, mais condições essa possui para arcar com os custos de informar de forma segmentada. Entretanto, uma das explicações possíveis para o sinal negativo encontrado no resultado desta pesquisa refere-se a hipótese de que quanto maior a empresa, menos ela divulga suas informações para evitar custos políticos. Watts e Zimmerman (1978) identificaram que as maiores empresas são mais sujeitas a intervenções do governo e por isso possuem maiores custos políticos em comparação as empresas menores. Dessa forma, para evitar chamar atenção do resultado e desempenho da empresa, os gestores das grandes empresas podem omitir informações para amenizar estes custos políticos.

A significância e o sinal positivo da varável Resultado Líquido evidenciam que as empresas com lucro no exercício divulgam mais informações por segmentos em comparação com as empresas que tiveram prejuízo. Este achado reforça os resultados de Aillón et al. (2013) e Souza (2013) e indica que as companhias omitem certas informações por segmento, quando possuem prejuízo, para evitar reportar algumas informações que possam estar relacionadas a certas ineficiências de gestão.

Em relação à governança corporativa, a variável foi significativa, porém o sinal obtido não era o esperado de acordo com a hipótese 3 , que fundamentava uma relação significativa e positiva em relação ao maior nível de governança corporativa com o ID em comparação aos demais níveis de governança. Os achados indicam o contrário, ou seja, que as empresas do nível Novo Mercado possuem o índice de divulgação menor que as empresas dos demais níveis de governança.

Apesar de não ser o resultado esperado, este achado corrobora com Schvirck (2014), que evidenciou um decréscimo informacional quando o nível de governança era maior. $O$ autor verificou que as empresas do nível 2 evidenciaram mais informações que as empresas do nível 1 e do novo mercado, e que as empresas do nível 2 divulgaram mais que as empresas do novo mercado (N2>N1>NM).

A variável Concentração Acionária também foi significativa a 1\%, evidenciando uma relação com o 
índice de divulgação. O sinal positivo do coeficiente mostra que quanto mais concentrado for o controle acionário da empresa, maior é o nível de divulgação dela. Este resultado não era esperado, pois de acordo com a fundamentação da hipótese 4, esperava-se que as empresas com ações mais difundidas poderiam evidenciar mais informações para suprir a necessidade informacional de todos os investidores.

A variável Endividamento foi significativa a $1 \%$ e é a variável que mais influencia o índice de divulgação. Há uma relação positiva entre o endividamento e o ID, o que confirma a H5 da pesquisa. Este resultado corrobora a argumentação de latridis (2008) de que empresas que precisam de recursos melhoram suas divulgações para obter a confiança de seus credores. Souza (2013) e Souza, Schäfer e Gasparetto (2016) também evidenciaram uma relação positiva entre endividamento e o índice de divulgação, diferentemente de Schvirck (2014) e Weschenfelder e Mazzioni (2014) que não encontraram essa relação.

A hipótese 6, que fundamenta uma relação positiva entre a índice de divulgação e a quantidade de segmentos reportados, não pode ser rejeitada. O coeficiente positivo indica que quanto mais segmentos a empresa tiver, maior é seu índice de divulgação. Essa relação pode ser uma consequência de que quanto mais segmentada for uma empresa, mais informações ela tem para repassar aos seus usuários, então estas empresas podem possuir melhores sistemas de organização de informações. Empresas com poucos segmentos divulgam menos, pois as informações, às vezes, são semelhantes as informações consolidadas.

Os achados mostram que as empresas que possuem clientes significativos divulgam mais que as empresas que possuem receitas totalmente pulverizadas. Isto pode ser evidência de que essas empresas divulgam mais informações para mostrar confiabilidade ou credibilidade no mercado e assim evitar perder seus clientes significativos.

As dummies representativas das empresas que divulgam prioritariamente por região geográfica ou por área de negócio tiveram significância. O coeficiente da dummy região geográfica é de 12,27 e o coeficiente da dummy Área de Negócio é de 6,90. Como o coeficiente da dummy região geográfica é maior, isso indica que as empresas que priorizam divulgar por região geográfica possuem índice de divulgação maior que as companhias que divulgam por área de negócio ou que divulgam de ambas as formas.

Algumas empresas que divulgam por região geográfica são a Ambev, WEG e Natura. Estas empresas possuem operações em outros países e um grande cartel de clientes. Isso pode acarretar o acréscimo da necessidade informacional do mercado, pois como operam em outros países a quantidade de usuários da informação aumenta. Dessa forma, o resultado evidencia que essas empresas divulgam mais que as outras como uma forma de suprir a necessidade de informações de seus diversos usuários.

As variáveis $A D R$ e independência do conselho de administração não foram significativas, o que indica que não há diferenças no índice de divulgação entre as empresas que possuem ADR e as empresas que não possuem, e que a independência do conselho de administração não influencia no índice de divulgação.

Os achados desta pesquisa, qualitativo e quantitativo, estão de acordo com certas teorias ou hipóteses consolidadas na literatura. Watts e Zimmerman (1978) explanam que uma das escolhas contábeis realizadas pelos gestores está relacionada com a redução dos custos políticos, principalmente das grandes empresas. Foi evidenciado aqui, que quanto maior for a empresa menor é o índice de divulgação dela, o que pode ser uma consequência dessas escolhas contábeis para diminuir os custos políticos.

Foi evidenciado que determinadas informações são divulgadas por poucas empresas, como a participação de cada segmento nos resultados de empresas coligadas, ou o detalhamento do resultado financeiro dos segmentos. Aparentemente os gestores não divulgam certas informações como forma de evitar evidenciar suas estratégias de mercado. As escolhas contábeis, descrita no referencial teórico desta pesquisa, abordam que os gestores tendem a divulgar apenas o que pode trazer benefícios próprios.

Pesquisas anteriores evidenciam a importância da divulgação voluntária ou obrigatória na redução da assimetria informacional, porém os estudos sobre a divulgação das informações por segmento requeridas pelo CPC 22 indicam baixos a médios índices de divulgação das empresas. Dessa forma, vale questionar se as informações por segmentos reportadas pelas empresas brasileiras são suficientes para reduzir a assimetria informacional.

Resultados anteriores afirmam que as informações contábeis divulgadas são influenciadas pela regulação, porém observa-se que em todos os anos de análise todas as empresas divulgaram menos que 0 solicitado. Esse fato leva ao questionamento sobre até que ponto a regulação influencia o reporte das informações contábeis e o quão forte a regulação precisa ser para gerar resultados satisfatórios nas divulgações das empresas.

A comparação dos resultados obtidos por esta pesquisa com os estudos de Silva e Pinheiro (2012), Aillón et al. (2013), Souza (2013), Schvirck (2014), Weschenfelder e Mazzioni (2014) e Souza, Shafer e Gaspareto (2016) mostra algumas diferenças sob o ponto de dos resultados quantitativos e qualitativos.

Em relação ao poder explicativo do modelo é possível fazer as seguintes suposições para explicar as causas que geraram um poder preditivo $\left(\mathrm{R}^{2}\right.$ de $\left.38,76 \%\right)$ maior neste estudo ao comparar com os estudos anteriores:

1) Utilização de variáveis novas no modelo (Independência do Conselho, Quantidade de Segmentos, Clientes Significativos, Área de Negócio e Região Geográfica). Observa-se que apenas a variável Independência do Conselho não foi significativa, ou seja, as demais novas variáveis, por serem significativas, 
incrementaram poder explicativo ao modelo geral.

2) Período estudado. Dentre os estudos anteriores listados, quatro deles utilizaram apenas um período, um estudo utilizou dois períodos, um estudo utilizou quatro períodos e a presente pesquisa teve um total de sete períodos analisados. Dessa forma, uma análise temporal mais ampla pode ter possibilitado captar com mais eficácia as relações entre as variáveis independentes com o nível de divulgação das empresas.

3) Exclusões das empresas financeiras. As empresas financeiras possuem diversas características contábeis, tributárias, operacionais e financeiras distintas das demais empresas, como por exemplo: a) alíquotas diferenciadas de CSLL, que afetam o resultado da empresa; b) as instituições financeiras trabalham de forma mais alavancada que as demais empresas, pois possui altos valores de capital de terceiros, que faz parte de suas operações. Isso pode acarretar significativas diferenças na mensuração do endividamento das empresas e consequentemente afetar os parâmetros da regressão.

Acrescentando também os estudos de Schvirck, Lunkes e Gasparetto (2013), Souza e Sarlo Neto (2014) e Pinheiro e Boscov (2015), é possível destacar que o percentual de empresas que publicaram informações por segmento foi maior neste estudo (81\%) do que nos demais. As pesquisas anteriores já identificaram um aumento na divulgação com o passar dos anos, e a presente pesquisa incorpora anos mais recentes e confirma esta evolução na divulgação. O ID médio calculado não foi o maior, porém foi acima de $50 \%$. Por outro lado, foi identificado o maior ID máximo (86,6\%).

Todos os estudos evidenciaram uma diferença significativa entre o percentual de empresas que reportam as informações por segmento por produtos e serviços (acima de 65\%) e as empresas que reportam por região geográfica (abaixo de $26 \%$ ) ou por ambas as formas. Cabe destacar que as empresas que divulgam por região geográfica possuem em média um ID maior que as demais empresas, conforme evidenciado nos achados quantitativos, ou seja, é possível afirmar que as empresas que possuem operações em diversas regiões e que controlam as informações por segmentos conforme as regiões, divulgam mais informações que as demais empresas.

De modo geral, as categorias ou itens mais divulgados na maioria das pesquisas estão relacionados com os critérios de identificação dos segmentos; com as receitas de clientes externos; e os tipos de produto e serviços de cada segmento. Já os itens ou categorias menos divulgadas são: dependência de seus principais clientes (clientes que representam pelo menos $10 \%$ da receita auferida); informações de equivalência patrimonial de coligadas e controladas; mensuração de transações realizadas entre os segmentos; e receitas e despesas financeiras.

Outro ponto a ressaltar é o item "dependência dos principais clientes", que é uma exigência normativa para que a empresa informe se há dependência de algum ou alguns clientes, ou se não há dependência. Provavelmente, poucas empresas evidenciam esta informação para evitar análises negativas sobre elas, pois empresas altamente dependentes de poucos clientes normalmente são mais arriscadas, porque a perda do cliente poderia afetar fortemente o desempenho da empresa.

Mesmo com a baixa divulgação da dependência de clientes, as empresas que forneceram essas informações possuem um ID médio maior que as demais empresas (resultado indicado pelo coeficiente positivo na regressão). Dessa forma, as empresas que possuem clientes significativos tendem a fornecer mais informações por segmento como uma forma fortalecer a confiabilidade e a credibilidade da empresa em relação aos seus clientes e usuários.

\section{Conclusão}

Esta pesquisa objetivou identificar quais características das empresas brasileiras são relacionadas com o índice de divulgação das informações por segmento de acordo com o CPC 22. Para isso, as empresas da Brasil, Bolsa, Balcão - B3 listadas no índice IBrX-50 (base 2017) foram analisadas, tanto qualitativamente, quanto quantitativamente.

O objetivo da pesquisa foi atingido, pois foi verificado que as variáveis Ln Ativo Total, Resultado Líquido, Endividamento, Concentração Acionária, Clientes Significativos, Segmento Primário, Quantidade de Segmentos e Governança Corporativa explicam a variação do índice de divulgação das empresas.

É válido questionar o nível de divulgação das empresas brasileiras em relação as informações por segmentos. A literatura vem indicando, de modo geral, baixos percentuais de divulgação quando comparados aos requisitos obrigatórios do CPC 22. Ressalta-se que a maioria dos itens do checklist são exigências obrigatórias, por isso era esperado índices de divulgação maiores.

Os resultados encontrados podem indicar falta de fiscalização dos órgãos reguladores e das firmas de auditoria, que aprovam as demonstrações contábeis para o reporte, mesmo com várias informações faltantes, dado que se infere que o normatizador considerou relevante para os usuários a evidenciação das informações requeridas pela norma.

Barth, Landsman e Lang (2008) explanam que melhorar as práticas contábeis, aumentar a transparência e a comparabilidade das demonstrações contábeis são uns dos objetivos dos órgãos reguladores e normatizadores. Os achados deste estudo indicam que talvez esses objetivos ainda não tenham sido alcançados completamente, pois as informações por segmentos são evidenciadas nas notas explicativas com estruturas diferentes de empresa para empresa, o que dificulta a comparabilidade. Muitas informações 
exigidas pelo CPC 22 não foram divulgadas, o que afeta a transparência. Uma regulação mais forte pode trazer resultados positivos em relação à divulgação das companhias.

A assimetria informacional que surge a partir da facilidade de acesso as informações internas das empresas por parte dos gestores, enquanto que os acionistas não possuem fácil acesso, pode ser amenizada pelas informações contábeis padronizadas (CHUNG, 1999). Dessa forma, as informações exigidas pelo CPC 22, padronizada pelo IFRS, também servem para reduzir essa assimetria. Entretanto, esta redução pode estar sendo prejudicada, pois muitas informações estão sendo omitidas dos investidores.

A literatura sobre as escolhas contábeis indica que as empresas podem escolher divulgar certas informações apenas se existir uma possibilidade de obter algum tipo de benefício, ao mesmo tempo que as empresas evitam divulgar algum tipo de informação que pode prejudicá-la. Os achados desta pesquisa evidenciam que as informações por segmento mais gerais das empresas, como a receita ou ativo total, são as mais divulgadas. Dificilmente essas informações prejudicam as empresas, porém outras informações como o detalhamento do resultado financeiro ou os critérios de agregação dos segmentos reportáveis podem externar determinadas estratégias corporativas. Por isso, essas informações foram as menos reportadas pelas companhias.

Alguns questionamentos que podem ser levados em consideração: será que há um excesso de informações solicitadas pelo CPC? Será que as informações que as empresas divulgam já não são suficientes para os usuários contábeis? Se as empresas divulgassem $100 \%$ das informações solicitadas, estas informações seriam relevantes?

O estudo sobre os índices de divulgação das empresas é pertinente não só para verificar se as empresas estão divulgando ou não as informações, mas também para chamar a atenção de como os processos atuais estão acontecendo. Cazzari (2013) identificou indícios de que é necessário muito tempo para a compreensão das notas explicativas das empresas, o que pode aumentar o custo de transação. $O$ autor também identificou que há excesso de informações divulgadas. Talvez o reporte de menos informações, porém as mais importantes, fizesse estas informações serem mais úteis, que é justamente o objetivo da contabilidade: gerar informações financeiras e contábeis úteis para a sociedade.

Esta pesquisa contribui para expandir os conhecimentos sobre as particularidades da divulgação das informações por segmento das empresas e quais características corporativas influenciam esta divulgação. Há contribuições metodológicas, pois novas variáveis foram abordadas nos modelos econométricos, além de a variável dependente ter sido tratada de forma diferente. Os achados contribuem para a evolução da teoria da divulgação principalmente de forma endógena, considerada por Dye (2011) a vertente mais importante da teoria. Os resultados também estão de acordo com os estudos sobre escolhas contábeis sobre a divulgação das informações.

Assim, o estudo traz contribuições práticas para o mercado, na medida que expõe quais categorias foram mais bem divulgadas e, principalmente, aquelas menos presentes na evidenciação, fato que pode comprometer o processo de decisão de analistas e investidores. De outra maneira, pode contribuir para analistas e investidores para demandar das empresas as informações normalmente omitidas. Esse processo, por sua vez, alimenta o processo normativo, permitindo que os órgãos normatizadores possam se utilizar da pesquisa para rever a efetividade da norma.

As principais limitações deste estudo estão relacionadas aos dados. A amostra é composta de maneira não aleatória, o que impede de fazer inferências para todas as empresas brasileiras, ou seja, os resultados refletem apenas as empresas analisadas. $O$ estudo foi realizado sobre as empresas de um determinado índice o que pode gerar consequências nos resultados provenientes das similaridades entre estas empresas.

Como sugestões para pesquisas futuras, seria aumentar a quantidade de empresas analisadas e identificar outras variáveis que podem explicar o índice de divulgação, pois o conjunto de variáveis significativas neste estudo explicam $41 \%$ do índice de divulgação, ou seja, há em torno de $60 \%$ para ser explicado por outras variáveis.

Também seria interessante elaborar estudos que pudessem responder os questionamentos supracitados. Verificar com os usuários das informações contábeis se eles utilizam as informações por segmentos para a tomada de decisão. Verificar se há excesso de cobrança por parte do CPC. Identificar os prováveis motivos para o índice de divulgação não atingir 100\% nas pesquisas realizadas na literatura.

\section{Referências}

AILLÓN, H. S.; SILVA, J.O.; PINZAN, A. F.; WUERGES, A. F. E. Análise das informações por segmento: divulgação de informações gerenciais pelas empresas brasileiras. Revista Contemporânea em Contabilidade, v. 10, n. 19, p. 33-48, jan./abr. 2013. DOI: http://dx.doi.org/10.5007/21758069.2013v10n19p33

ALMEIDA, J. E. F. Qualidade da informação contábil em ambientes competitivos. 2010. Tese (Doutorado em Controladoria e Contabilidade) - Programa de Pós-Graduação em Ciências Contábeis, Faculdade de Administração, Economia e Contabilidade da Universidade de São Paulo. São Paulo, 2010. 
ALMEIDA, S. R.; SILVA, R. P. A.; ALVES, K. R. C. P.; OLIVEIRA, K. P. S. Informações por segmento: aspectos informativos e gerenciais nas entidades do setor de construção civil listadas na BM\&FBovespa. Qualitas Revista Eletrônica. v. 16, n. 2, p. 73-90, jul./set. 2015. DOI:

http://dx.doi.org/10.18391/req.v16i2.2767

ARCHAMBAULT, J. J.; ARCHAMBAULT, M. E. A multinational test of determinants of corporate disclosure. The International Journal of Accounting, v. 38, n. 1, p. 173-194, 2003. DOI:

https://doi.org/10.1016/S0020-7063(03)00021-9

BALL, R.; KOTHARI, S. P.; ROBIN, A. The effect of international institutional factors on properties of accounting earnings. Journal of Accounting and Economics. v. 29, p. 1-51, fev. 2000. DOI: https://doi.org/10.1016/S0165-4101(00)00012-4

BARTH, M. E.; LANDSMAN, W. R.; LANG, M. H. International accounting standards and accounting quality. Journal of Accounting Research. v. 46, n. 3, p. 467-498, jun. 2008. DOI: https://doi.org/10.1111/j.1475679X.2008.00287.x

BEAVER, W. H. Financial reporting: an accounting revolution. New Jersey: Prentice-Hall, 1998, $180 \mathrm{f}$.

BLANCO, B.; LARA, J. M. G.; TRIBÓ, J. The relation between segment disclosure and earnings quality. Journal of Accounting and Public Policy. v. 33, p. 449-469, set./out. 2014. DOI:

http://dx.doi.org/10.1016\%2Fj.jaccpubpol.2014.06.002

BOSCOV, C. P. O enfoque gerencial na divulgação de informações por segmento. 2009. Dissertação (Mestrado em Controladoria e Contabilidade) - Faculdade de Economia, Administração e Contabilidade da Universidade de São Paulo. São Paulo, 2009.

BOWEN. R. M.; DUCHARME, L.; SHORES, D. Economic and industry determinants of accounting method choice. (Working Paper). University of Washington Business School, 1999.

CAZZARI, R. B. A compreensibilidade das informações contábeis e sua relação com os custos de transação sob a óptica dos profissionais de investimento. 2013. Dissertação (Mestrado em Controladoria e Contabilidade: Contabilidade) - Faculdade de Economia, Administração e Contabilidade, Universidade de São Paulo, São Paulo. 2013.

CHRISTIE, A. A.; ZIMMERMAN, J. L. Efficient and opportunistic choices of accounting procedures: corporate control contests. The Accounting Review. v. 69, n. 4, p. 539-566, out. 1994. DOI: www.jstor.org/stable/248431

CHUNG, D. Y. The informational effect of corporate lobbying against proposed accounting standards. Review of Quantitative Finance and Accounting. v. 12, n. 3, p. 243-269, mai. 1999. DOI: https://doi.org/10.1023/A:1008374831913

COMITÊ DE PRONUNCIAMENTOS CONTÁBEIS. Pronunciamento Técnico CPC 22 - Informações por Segmento. jul. 2009.

CRUZ, A. P. C.; MACHADO, E. A.; PEREIRA, A. F.; OLEIRO, W. N.; CARVALHO, L. N. Empresas brasileiras do novo mercado e suas práticas de evidenciação voluntária de informações por segmento. Sinergia. Rio Grande, v. 18, n. 2, p. 19-35, 2014.

DYE, R. A. An evaluation of "essays on disclosure" and the disclosure literature in accounting. Journal of Accounting and Economics. Burlington, v. 32, p. 181-235. 2001. DOI: https://doi.org/10.1016/S01654101(01)00024-6

EISENHARDT, K. Agency theory: an assessment and review. Academy of Management Review. v. 14, n. 1, p. 57-74. 1989. DOI: https://doi.org/10.5465/amr.1989.4279003

EMMANUEL, C. R.; GARROD, N. On the relevance and comparability of segmental data. Abacus, v. 38, n. 2, p. 215-234, jun. 2002. DOI: https://doi.org/10.1111/1467-6281.00106

FATH, K. T.; GAVSKI, D.; ORO, I. M.; SOTT, V. R. Informações por segmento de companhias brasileiras da BM\&FBOVESPA. In: CONGRESSO BRASILEIRO DE CUSTOS, 22., 2015, Foz do Iguaçu. Anais... Foz de Iguaçu: CBC, 2015.

FÁVERO, L. P.; BELFIORE, P.; SILVA, F. L.; CHAN, B. L. Análise de dados: modelagem multivariada para tomada de decisões. Rio de Janeiro: Elsevier, 2009, $544 \mathrm{f}$.

FERNANDES, L. J. D. Segmentação de negócios: fonte de informação para os usuários das demonstrações contábeis de empresas petrolíferas. 2009. Dissertação (Mestrado em Ciências Contábeis) Centro de Ciências Jurídicas e Econômicas, Faculdade de Administração e Ciências Contábeis,

Universidade Federal do Rio de Janeiro, Rio de Janeiro, 2009. 
FERREIRA, E. M. Evidenciação por segmento de negócio: uma análise das companhias integradas de óleo e gás listadas na NYSE (bolsa de valores de Nova York). 2011. Dissertação (Mestrado em Ciências Contábeis) - Programa Multiinstitucional e Inter-Regional de Pós-Graduação em Ciências Contábeis - área de concentração Mensuração Contábil - da Universidade de Brasília (UnB), da Universidade Federal da Paraíba (UFPB) e da Universidade Federal do Rio Grande do Norte (UFRN), Natal, 2011.

FIELDS, T. D.; LYS, T. Z.; VICENT, L. Empirical research on accounting choice. Journal of Accounting and Economics. v. 31, p. 255-307, jan. 2001. DOI: https://doi.org/10.1016/S0165-4101(01)00028-3

GUJARATI, D. N.; PORTER, D. C. Econometria básica. 5. ed. Porto Alegre: McGraw Hill, 2011, 924 f.

HEALY, P.; PALEPU, K. Information asymmetry, corporate disclosure and capital markets: a review of empirical disclosure literature. Journal of Accounting and Economics. v. 31, p. 405-440. 2001. DOI: https://doi.org/10.1016/S0165-4101(01)00018-0

IATRIDIS, G. Accounting disclosure and firms' financial attributes: evidence from the UK stock market. International Review of Financial Analysis. v. 17, p. 219-241, 2008. DOI:

https://doi.org/10.1016/j.irfa.2006.05.003

IUDÍCIBUS, S.; MARTINS, E.; CARVALHO, L. N. Contabilidade: aspectos relevantes da epopeia de sua evolução. Revista Contabilidade \& Finanças. São Paulo, v. 16, n. 38, p. 7-19, mai/ago. 2005. DOI: https://doi.org/10.1590/S1519-70772005000200002

IUDÍCIBUS, S.; MARTINS, E.; GELBCKE, E. R.; SANTOS, A. Manual de contabilidade societária: aplicável a todas as sociedades de acordo com as normas internacionais e do CPC. São Paulo: Atlas, 2010, $824 \mathrm{f}$.

INTERNATIONAL ACCOUNTING STANDARDS BOARD. International Financial Reporting Standards 8: operational segments. nov., 2006.

JENSEN, M. C.; MECKLING, W. H. The theory of the firm: managerial behavior, agency costs, and ownership structure. Journal of financial economics. v. 3, n. 4, p. 305-360. 1976. DOI: https://doi.org/10.1007/978-94-009-9257-3_8

KANG, H.; GRAY, S. J. Segment reporting practices in Australia: has IFRS 8 made a difference? Australian Accounting Review. Australia, v. 23, n. 3, 2013. DOI: https://doi.org/10.1111/j.1835-2561.2012.00173.x

KOU, W.; HUSSAIN, S. Predictive gains to segmental disclosure matrices, geographic information and industry sector comparability. The British Accounting Review, v. 39, n. 3, p. 183-195, set. 2007. DOI: https://doi.org/10.1016/j.bar.2007.05.002

LAMBERT, R. C.; LEUZ, C.; VERRECCHIA, R. A. Accounting information, disclosure and de cost of capital. Journal of Accounting Research. v. 45, p. 385-420. 2007. DOI: https://doi.org/10.1111/j.1475679X.2007.00238.x

LÉLIS, D. L. M.; COLAUTO, R. D.; PINHEIRO, L. E. T.; JORDÃO, R. V. D. Evidenciação de informações financeiras: estudo empírico em empresas brasileiras dos setores de telecomunicações e consumo nãocíclico. In: CONGRESSO DE CONTABILIDADE E AUDITORIA DE PORTUGAL, 12. 2008, Coimbra.

Anais... Coimbra, Portugal, 2008. CD-ROM.

LEV, B. Toward a theory of equitable and efficient accounting policy. The Accounting Review. v. 63, n. 1, p. 1-22. 1988. DOI: www.jstor.org/stable/247676

LEVITT, A. The importance of high quality accounting standards. Accounting Horizons. v. 12, n. 1, p. 7982, mar. 1998.

MACAGNAN, C. B. Evidenciação voluntária: fatores explicativos da extensão da informação sobre recursos intangíveis. Revista Contabilidade \& Finanças. São Paulo, v. 20, n. 50, p. 46-61, mai/ago. 2009. DOI: https://doi.org/10.1590/S1519-70772009000200004

MACKENZIE, B.; COETSEE, D.; NJIKIZANA, T.; CHAMBOKO, R.; COLYVAS, B.; HANEKOM, B. IFRS 2012: interpretação e aplicação. Porto Alegre: Bookman, 2013.

MAIER, S. M.; SCHÄFER, J. D.; GASPARETTO, V. CPC 22: um estudo sobre a divulgação de informações de preço de transferência em empresas da BM\&FBOVESPA. Pensar Contábil. Rio de Janeiro, v. 19, n. 68, p. 47-56, jan./abr. 2017.

MOURA, G. D.; FRANZ, L.; CUNHA, P. R. Qualidade da informação contábil em empresas familiares: influência dos níveis diferenciados de governança da BM\&FBOVESPA, tamanho e independência do conselho de administração. Contaduría y Administración. v. 60, n. 2, p 423-446, abr./jun. 2015. DOI: https://doi.org/10.1016/S0186-1042(15)30008-5 
MOURAD, N. A. IFRS 8: segmentos operacionais: contabilidade internacional: International Financial Reporting Standards - IFRS. São Paulo: Atlas, 2009.

MURCIA, F. D.; SANTOS. A. Fatores determinantes do nível de disclosure voluntário de companhias abertas no Brasil. Revista de Educação e Pesquisa em Contabilidade, Brasília, v. 3, n. 2, p. 72-95, mai./ago. 2009. DOI: https://doi.org/10.17524/repec.v3i2.68

PERLINGEIRO, B. C. L. Teoria das escolhas contábeis: fair value de derivativos em bancos no Brasil. 2009. Dissertação (Mestrado em Controladoria e Contabilidade: Contabilidade) - Faculdade de Economia, Administração e Contabilidade, Universidade de São Paulo. São Paulo, 2009

PINHEIRO, V. A. A.; BOSCOV, C. P. Análise de informações por segmento das empresas premiadas pelo troféu transparência ANEFAC/FIPECAFI/SERASA 2013. ConTexto. Porto Alegre, v. 15, n. 29, p. 96-112, jan./abr. 2015.

POHLMANN, M. C.; ALVES, F. J. S. Regulamentação. In: IUDÍCIBUS, S.; LOPES, A. B. (Orgs.). Teoria avançada da contabilidade. São Paulo: Atlas, 2004. p. 233- 273.

SALOTTI, B. M.; YAMAMOTO, M. M. Ensaio sobre a teoria da divulgação. BBR - Brazilian Business Review. Vitória, v. 2, n. 1, p. 53-70, jan./jun. 2005. DOI: https://doi.org/10.15728/bbr.2005.2.1.4

SCHVIRCK, E. Relatórios por segmentos publicados pelas companhias de capital aberto no Brasil os efeitos da divulgação no desempenho das empresas. 2014. Tese (Doutorado em Administração) Programa de Pós-Graduação em Administração da Universidade Federal de Santa Catarina, Florianópolis, 2014.

SCHVIRCK, E.; LUNKES, R. J.; GASPARETTO, V. Divulgação de informações por segmento: panorama da aplicação do CPC 22. Revista de Educação e Pesquisa em Contabilidade, Brasília, v. 7, n. 2, p. 131-146, abr./jun. 2013. DOI: https://doi.org/10.17524/repec.v7i2.571

SCOTT, W. R. Financial accounting theory. 6. Ed. Toronto: Prentice Hall, 2012, $571 \mathrm{f}$.

SILVA, D. A; PINHEIRO, L. E. T. Estágio atual de evidenciação e fatores que influenciam o disclosure de informações por segmentos por empresas brasileiras. Revista de Contabilidade e Controladoria. Curitiba, v. 4, n. 3, p. 78-94, set./dez. 2012. DOI: http://dx.doi.org/10.5380/rcc.v4i3.29897

SILVA, P. D. A; MARQUES, J. A. V. C.; SANTOS, O. M. Análise da evidenciação das informações sobre o impairment dos ativos de longa duração de empresas petrolíferas. Revista de Administração e Contabilidade da Unisinos. v. 6, n. 3, p. 258-274, set/out. 2009.

SOUZA, J. A. Informações sobre segmentos operacionais no Brasil: práticas e determinantes de divulgação. 2013. Dissertação (Mestrado em Ciências Contábeis) - Centro de Ciências Jurídicas e Econômicas da Universidade Federal do Espírito Santo, Vitória, 2013.

SOUZA, J. A.; SARLO NETO, A. Práticas de divulgação de informações sobre segmentos operacionais no Brasil. Sociedade, Contabilidade e Gestão, Rio de Janeiro, v. 9, n. 2, p. 40-57, mai./ago. 2014.

SOUZA, P. V. S.; ALMEIDA, S. R. V. Fatores relacionados ao nível de disclosure das companhias brasileiras de capital aberto listadas na BM\&FBOVESPA. Revista Universo Contábil. Blumenau, v. 13, n. 2, p. 166-186, abr./jun. 2017. DOI: http://dx.doi.org/10.4270/RUC.2017214

SOUZA, T. S.; SCHAFER, J. D.; GASPARETTO, V. Análise do nível de evidenciação de informações por segmento das companhias brasileiras listadas no ibrx-50. Revista Ambiente Contábil. Rio Grande do Norte, v. 8, n. 2, p. 59-75, abr. 2016.

STEVENSON, W. J. Estatística Aplicada à Administração. São Paulo: Harbra, 1981.

TALHA, M.; SALIM, A. S. What prompts firms to choose between business and geographic segments as a primary segment? Managerial Auditing Journal. v. 25, n. 1, p. 17-31. 2010. DOI:

https://doi.org/10.1108/02686901011007289

VASCONSELOS, M. G.; SZUSTER, N. Informações contábeis por segmento de negócios. Revista de Contabilidade do Mestrado em Ciências Contábeis da UERJ, Rio de Janeiro, v.8, n.2, p. 71-88, 2003.

VERRECCHIA, R. E. Essays on disclosure. Journal of Accounting and Economics. v. 32, p. 97-180, 2001. DOI: https://doi.org/10.1016/S0165-4101(01)00025-8

WATTS, R. L. Accounting choice theory and market-based research in accounting. British Accounting Review. v. 24, n. 3, p. 235-267, set. 1992. DOI: https://doi.org/10.1016/S0890-8389(05)80023-X

WATTS, R. L.; ZIMMERMAN, J. L. Towards a positive theory of the determination of accounting standards. The Accounting Review. v. 53, n. 1, p. 112-134, jan. 1978. DOI: https://www.jstor.org/stable/245729 
WESCHENFELDER, C.; MAZZIONI, S. Informações por segmento: análise do nível de evidenciação das companhias listadas no novo mercado. Revista Catarinense da Ciência Contábil, Florianópolis, v.13, n.39, p. 21-33, maio/ago. 2014. DOI: http://dx.doi.org/10.16930/2237-7662/rccc.v13n39p21-33

\section{NOTAS}

\section{AGRADECIMENTOS}

Os autores agradecem à CAPES e aos avaliadores anônimos que contribuíram para a melhoria do artigo.

\section{CONTRIBUIÇÃO DE AUTORIA}

Concepção e elaboração do manuscrito: P. P. Nunes, O. M. Santos

Coleta de dados: P. P. Nunes

Análise de dados: P. P. Nunes, O. M. Santos e J. A. V. C, Marques

Discussão dos resultados: P. P. Nunes, O. M. Santos e J. A. V. C, Marques

Revisão e aprovação: P. P. Nunes, O. M. Santos e J. A. V. C, Marques

\section{CONJUNTO DE DADOS DE PESQUISA}

O conjunto de dados que dá suporte aos resultados deste estudo não está disponível publicamente.

\section{FINANCIAMENTO}

A autora Priscila Pontes Nunes contou com bolsa da CAPES durante o curso de mestrado, sendo o artigo derivado de sua dissertação de mestrado, em conformidade com a Portaria $n^{\circ} 206$, de 4 de setembro de 2018, "o presente trabalho foi realizado com apoio da Coordenação de Aperfeiçoamento de Pessoal de Nível Superior - Brasil (CAPES) - Código de Financiamento 001".

\section{CONSENTIMENTO DE USO DE IMAGEM}

Não se aplica.

\section{APROVAÇÃO DE COMITÊ DE ÉTICA EM PESQUISA \\ Não se aplica.}

\section{CONFLITO DE INTERESSES}

Não se aplica.

\section{LICENÇA DE USO}

Os Direitos Autorais para artigos publicados neste periódico são do autor, com direitos de primeira publicação para a Revista. Em virtude de aparecerem nesta Revista de acesso público, os artigos são de uso gratuito, com atribuições próprias, em aplicações educacionais, de exercício profissional e para gestão pública. A Revista adotou a licença Creative Commons Atribuição 4.0 Internacional - CC BY NC ND. Esta licença permite acessar, baixar (download), copiar, imprimir, compartilhar, reutilizar e distribuir os artigos desde que com a citação da fonte, atribuindo os devidos créditos de autoria. Nesses casos, nenhuma permissão é necessária por parte dos autores ou dos editores. Autores têm autorização para assumir contratos adicionais separadamente, para distribuição não-exclusiva da versão do trabalho publicada nesta revista (ex.: publicar em repositório institucional ou um capítulo de livro).

\section{PUBLISHER}

Universidade Federal de Santa Catarina. Curso de Ciências Contábeis e Programa de Pós-graduação em Contabilidade. Publicação no Portal de Periódicos UFSC. As ideias expressadas neste artigo são de responsabilidade de seus autores, não representando, necessariamente, a opinião dos editores ou da universidade.

\section{EDITORES}

Carlos Eduardo Facin Lavarda e Suliani Rover

\section{HISTÓRICO}

Recebido em: 01/04/2018 - Revisado por pares em: 08/08/2018 - Reformulado em: 04/05/2020 Recomendado para publicação em: 04/05/2020 - Publicado em: 30/05/2020 